\title{
Study on the Optimizing Operation of Exhaust Air Heat Recovery and Solar Energy Combined Thermal Compensation System for Ground-Coupled Heat Pump
}

\author{
Kuan Wang, Nianping Li, Jinqing Peng, and Yingdong He \\ College of Civil Engineering, Hunan University, Changsha, Hunan 410082, China \\ Correspondence should be addressed to Nianping Li; linianping@126.com and Jinqing Peng; jallenpeng@gmail.com
}

Received 9 August 2016; Revised 22 November 2016; Accepted 30 November 2016; Published 1 January 2017

Academic Editor: Angell A. Bayod

Copyright (C) 2017 Kuan Wang et al. This is an open access article distributed under the Creative Commons Attribution License, which permits unrestricted use, distribution, and reproduction in any medium, provided the original work is properly cited.

\begin{abstract}
This study proposed an exhaust air heat recovery and solar energy combined thermal compensation system (ESTC) for groundcoupled heat pumps. Based on the prediction of the next day's exhaust air temperature and solar irradiance, an optimized thermal compensation (OTC) method was developed in this study as well, in which the exhaust air heat recovery compensator and solar energy compensator in the ESTC system run at high efficiency throughout various times of day. Moreover, a modified solar term similar days group (STSDG) method was proposed to improve the accuracy of solar irradiance prediction in hazy weather. This modified STSDG method was based on air quality forecast and AQI (air quality index) correction factors. Through analyzing the operating parameters and the simulation results of a case study, the ESTC system proved to have good performance and high efficiency in eliminating the heat imbalance by using the OTC method. The thermal compensation quantity per unit energy consumption (TEC) of ESTC under the proposed method was 1.25 times as high as that under the traditional operation method. The modified STSDG method also exhibited high accuracy. For the accumulated solar irradiance of the four highest daily radiation hours, the monthly mean absolute percentage error (MAPE) between the predicted values and the measured values was $6.35 \%$.
\end{abstract}

\section{Introduction}

Ground-coupled heat pump (GCHP) systems are commonly utilized in many countries [1,2]. However, the efficiency of most of GCHP systems decreases over time due to underground thermal imbalance [3-6]. Previous researchers have addressed this problem from a variety of perspectives: increasing borehole spacing or depth, using ground heat exchangers in different zones or increasing the natural heat recovery time by reducing the operation time of each ground loop zone [7-10]. Existing solutions for underground thermal imbalance are useful but merit further improvement. Increasing borehole spacing is limited to geological conditions, construction difficulties, and engineering costs; reducing the operation time of ground heat exchangers in each area necessitates extra boreholes, requiring more space and raising initial costs [11, 12].

Many new buildings in China have been constructed with hybrid-GCHP systems designed to minimize underground thermal imbalance [13-15]. In cold regions, boilers or solar systems are often applied to compensate for hybrid-GCHP heating operation [1,16-21]. Boilers can effectively prevent cold accumulation in a hybrid-GCHP, but as they run on fossil fuels, their energy efficiency is low. Si et al. [22] analyzed the performance of a GCHP system assisted by solar collectors to find that supplementation with solar energy indeed keeps the system running efficiently over long-term operation. In another study on the use of solar collectors to supplement ground heat exchangers, scholars found that the combination effectively recovers the wall temperature of boreholes [23]. However, the stability, efficient working hours and effective heating loads of the solar thermal compensation and heating are not ideal enough for cold regions, due to the impact of hazy, cloudy weather conditions and low outdoor temperature $[24,25]$. Some new solar energy systems that show potential as compensators were developed in [26, 27]. However, these systems cannot work well enough during the cold winter months in northern China. Nonetheless, the 
TABLE 1: Main device status in three modes.

\begin{tabular}{|c|c|c|c|c|c|c|c|c|c|c|}
\hline Number & $\begin{array}{l}\text { Equipment } \\
\text { mode }\end{array}$ & $\begin{array}{c}\text { Electric } \\
\text { valve } \\
(\mathrm{V} 1)\end{array}$ & $\begin{array}{c}\text { Electric } \\
\text { valve } \\
\text { (V2) }\end{array}$ & $\begin{array}{c}\text { Electric } \\
\text { valve } \\
\text { (V3) }\end{array}$ & $\begin{array}{c}\text { Electric } \\
\text { valve } \\
\text { (V4) }\end{array}$ & $\begin{array}{c}\text { Electric } \\
\text { valve } \\
\text { (V5) }\end{array}$ & $\begin{array}{c}\text { Electric } \\
\text { valve } \\
\text { (V6) }\end{array}$ & $\begin{array}{l}\text { Electric } \\
\text { valve } \\
(\mathrm{V} 7, \mathrm{~V} 8)\end{array}$ & $\begin{array}{c}\text { Electric } \\
\text { air valve } \\
\text { (VA-1) }\end{array}$ & $\begin{array}{c}\text { Electric } \\
\text { air valve } \\
(\mathrm{VA}-2)\end{array}$ \\
\hline $\begin{array}{l}\text { Operation } \\
\text { mode } 1\end{array}$ & $\begin{array}{l}\text { Heating or } \\
\text { cooling }\end{array}$ & Off & Off & Off & On & On & On & Off & Off & On \\
\hline $\begin{array}{l}\text { Operation } \\
\text { mode } 2\end{array}$ & $\begin{array}{l}\text { Heating plus } \\
\text { thermal } \\
\text { compensation }\end{array}$ & On & On & Off & Off & On & On & On or off & On & Off \\
\hline $\begin{array}{l}\text { Operation } \\
\text { mode } 3\end{array}$ & $\begin{array}{c}\text { Thermal } \\
\text { compensation }\end{array}$ & On & Off & On & Off & Off & Off & On or off & On & Off \\
\hline
\end{tabular}

solar irradiance is sufficient during the nonheating seasons, especially in summer months. Although solar energy can be applied for heat compensation, thermal storage, and elimination of cold accumulation throughout the year, it is clearly that gathering solar energy could increase soil temperature and reduce the efficiency of the cooling system significantly in summer [24, 25, 28]. You et al. [29] attempted to resolve the GCHP thermal imbalance problem by designing an airsource heat compensator to solve the underground thermal imbalance of GCHP. However, the initial cost and extra operation energy consumption of the air-source heat compensator are relatively high. Wu et al. [30] reported that the groundsource absorption heat pump was superior to the groundsource electrical heat pump and the former could be used as a potential solution for eliminating the ground thermal imbalance of GCHP in cold regions. However, the groundsource absorption heat pump is not suitable for the buildings that required long-period cooling due to the relatively low coefficient of the performance for cooling.

Also, although numerous studies focusing on the exhaust air heat recovery have been conducted [31-33], few studies were reported to recover waste heat from the exhaust air of the electricity transformation and distribution (ETD) room. However, the exhaust air of ETD rooms is a good lowgrade energy resource for waste heat recovery and heat compensation, since its temperature is high and the ETD room runs on the same schedule as GCHP systems.

Aiming to improve the efficiency of the hybrid solar energy heat compensator for ground heat exchangers, this study proposed a new exhaust air heat recovery and solar energy combined thermal compensation system (ESTC) for ground-coupled heat pumps. A novel optimized thermal compensation (OTC) method based on parameters predictions was also developed correspondingly.

\section{ESTC-GCHP System}

2.1. ESTC-GCHP System. A schematic diagram of the ESTCGCHP is shown in Figure 1. This system integrates an exhaust air heat recovery unit (EAHRU) and a solar thermal collector on the ground heat exchanger loop of the conventional GCHP system for thermal compensation. The ESTC-GCHP has three different kinds of operating modes: heating (cooling) mode, heating plus heat recovery mode, and thermal compensation mode. Thermal compensation in the latter two modes can be achieved by the EAHRU and/or solar collector. The EAHRU also includes a by-pass air pipe and two switching air valves through which exhaust air is directly discharged in spring and summer. The status of each motor-driven valve under the three operation modes is shown in Table 1. In this study, the EAHRU uses the exhaust air from the ETD room as the air source, because the ETD room has high indoor temperature and runs on the same schedule as the heating system. Moreover, there is a complementary relationship between the ETD-EAHRU and the solar collector.

2.2. Corresponding Zone Scale of ESTC. The EAHRU system recovers and uses "free" dissipation heat of power distribution equipment in ETD room. Thus the EAHRU's thermal compensation capacity is essentially determined by the scale of the ETD room. For most of the GCHP-heating buildings which contain an ETD room or are close to a districtlevel ETD room, the EAHRU has a good chance to play an important role in heat compensation. The following equation was defined to estimate the heating load $\left(Q_{\mathrm{EAHRU}}\right)$ of the construction zone to be served by the EAHRU:

$$
Q_{\text {EAHRU }}=Q_{\text {tot }} \times \frac{Q_{\mathrm{re}}}{\left|Q_{\mathrm{AHE}}-Q_{\mathrm{AHR}}\right|} .
$$

$Q_{\mathrm{re}}, Q_{\mathrm{tot}}, Q_{\mathrm{AHE}}$, and $Q_{\mathrm{AHR}}$ in (1) can be determined by load simulation and the method in Section 3.1 during the HVAC design stage.

The capacity of solar collectors in the ESTC can be adjusted by increasing or decreasing the quantity of solar collectors. Thus, when designing and applying an ESTC system, it is necessary to estimate $Q_{\text {EAHRU }}$ and determine the corresponding building zone scale of the EAHRU system at first. After that, the scale of solar collectors can be determined. In this way, the heat compensation capacity of the EAHRU and ESTC could match not only the scale of the construction zone but also that of the corresponding ground heat exchanger zone.

\section{OTC Method}

For the purpose of improving the operation efficiency of the ESTC system, an optimized thermal compensation (OTC) method was developed in this section. To examine the 


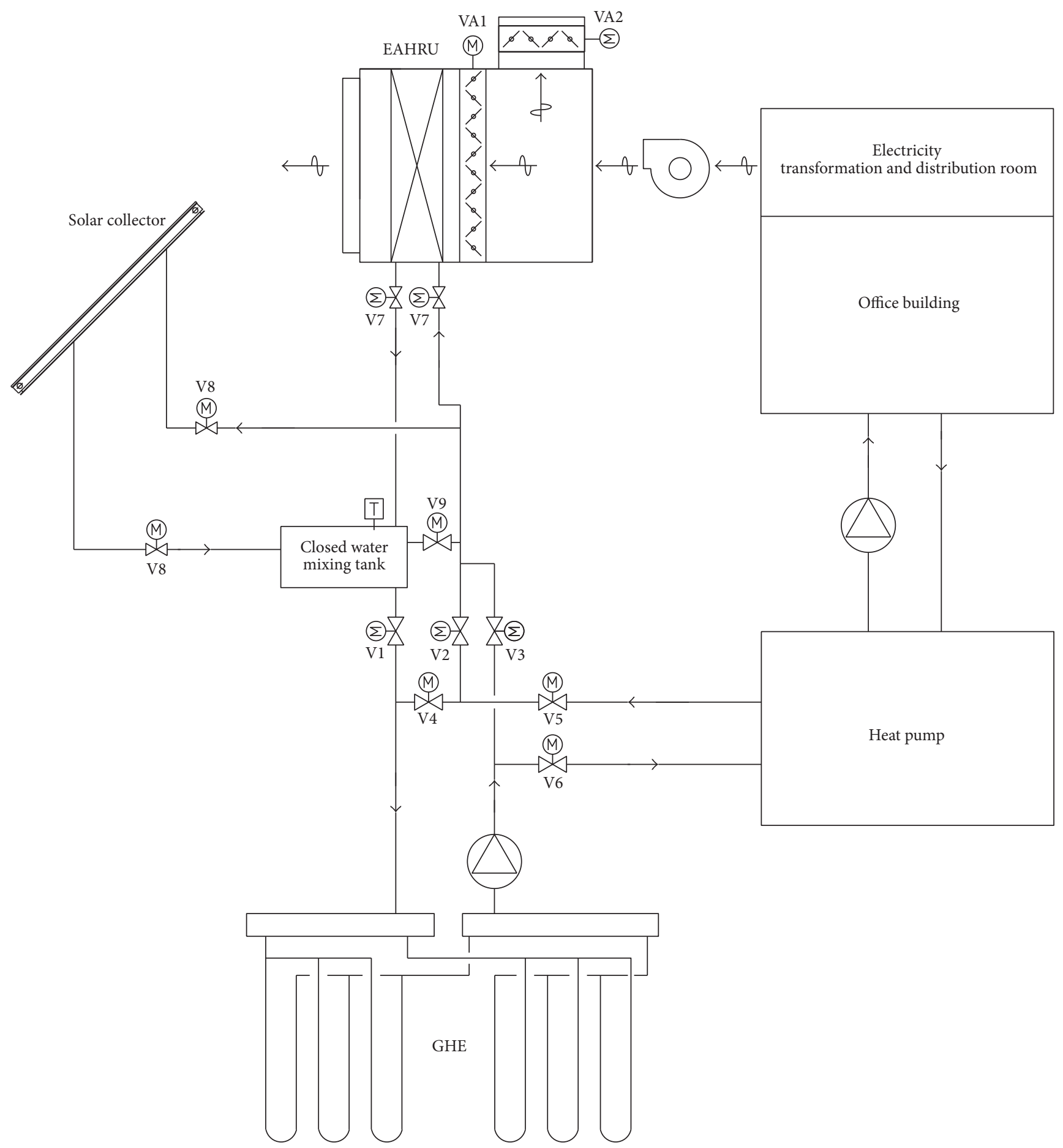

FIgURE 1: Schematic diagram of ESTC-GCHP.

necessity of the proposed OTC method, the daily variation tendency of ESTC thermal compensation capacity was discussed firstly.

\subsection{Thermal Compensation Capacity of the ESTC}

3.1.1. Capacity of the EAHRU. Due to the relatively low moisture content of the ETD room exhaust air, there was only sensible heat exchange process in the EAHRU examined here. The heat compensation capacity of the EAHRU can be calculated using the temperature of the exhaust air and the performance model provided by manufacturers. Figure 2 shows the calculated thermal compensation capacity of an EAHRU in a typical building in Beijing under $15^{\circ} \mathrm{C}$ inlet water temperature and various ETD room exhaust air temperatures on January 15, 2015. The thermal compensation capacity and 


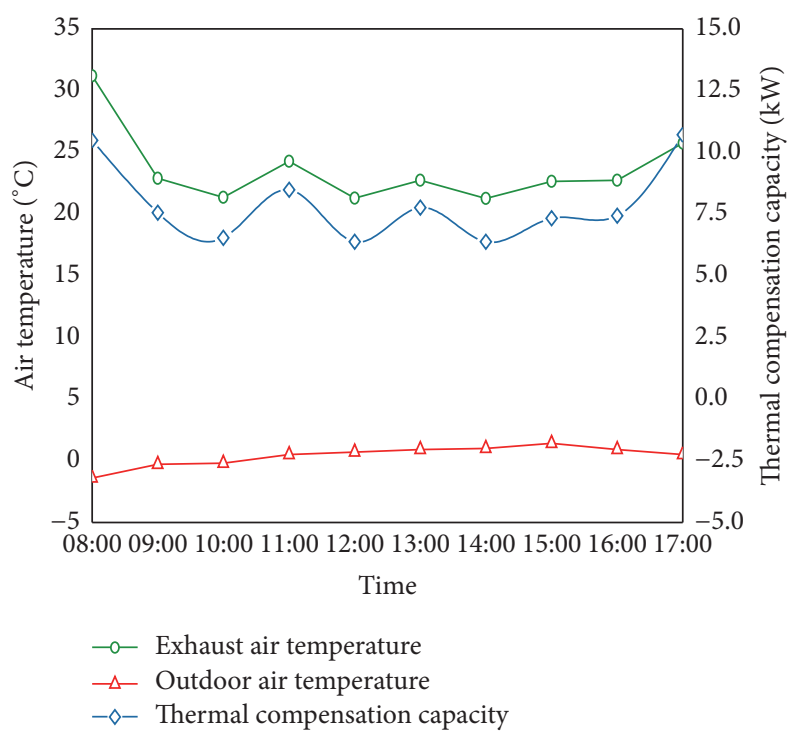

Figure 2: Thermal compensation capacity of ETD-EAHRU on January 15, 2015.

exhaust air temperature share similar trends and are almost entirely unaffected by outdoor temperatures.

3.1.2. Capacity of Solar Collectors. The capacity of solar collectors can be calculated by the following equations based on the performance model provided by manufacturers [34, 35]:

$$
Q_{H}=\frac{J_{T} \times \eta_{c} \times\left(1-\eta_{L}\right) \times A_{C}}{3600 \times f},
$$

where $Q_{H}$ is the heat-collecting capacity of the solar collector $(\mathrm{W}), J_{T}$ is the hourly solar irradiance quantity $\left(\mathrm{J} / \mathrm{m}^{2} \cdot \mathrm{h}\right), f$ is the solar fraction (\%), $\eta_{c}$ is the average efficiency of the solar collector based on the gross collector area (\%), $\eta_{L}$ is the heat loss rate of pipeline and heat storage device (\%), and $A_{C}$ is the gross collector area $\left(\mathrm{m}^{2}\right)$.

$$
\eta_{c}=\eta_{0}-a_{1} T^{*}-a_{2} G\left(T^{*}\right)^{2},
$$

where $\eta_{0}$ is the heat collector efficiency when $T^{*}=0(\%)$, $a_{1}$ is a constant with $T^{*}$ as a reference, $T^{*}$ is the normalized temperature difference $\left(\mathrm{m}^{2} \cdot \mathrm{K} / \mathrm{W}\right), a_{2}$ is a constant with $T^{*}$ as a reference, and $G$ is total solar irradiance $\left(\mathrm{W} / \mathrm{m}^{2}\right)$.

$$
T^{*}=\frac{t_{i}-t_{a}}{G},
$$

where $T^{*}$ is the normalized temperature difference $\left(\mathrm{m}^{2} \cdot \mathrm{K} /\right.$ $\mathrm{W}), t_{i}$ is the working medium inlet temperature of the solar collector $\left({ }^{\circ} \mathrm{C}\right)$, and $t_{a}$ is the ambient temperature $\left({ }^{\circ} \mathrm{C}\right)$.

Figure 3 shows the calculated thermal compensation capacities of solar collectors on a typical day as-calculated via (2)-(4). As shown in Figure 3, the thermal compensation capacity of the solar collectors changed with varying solar irradiance.

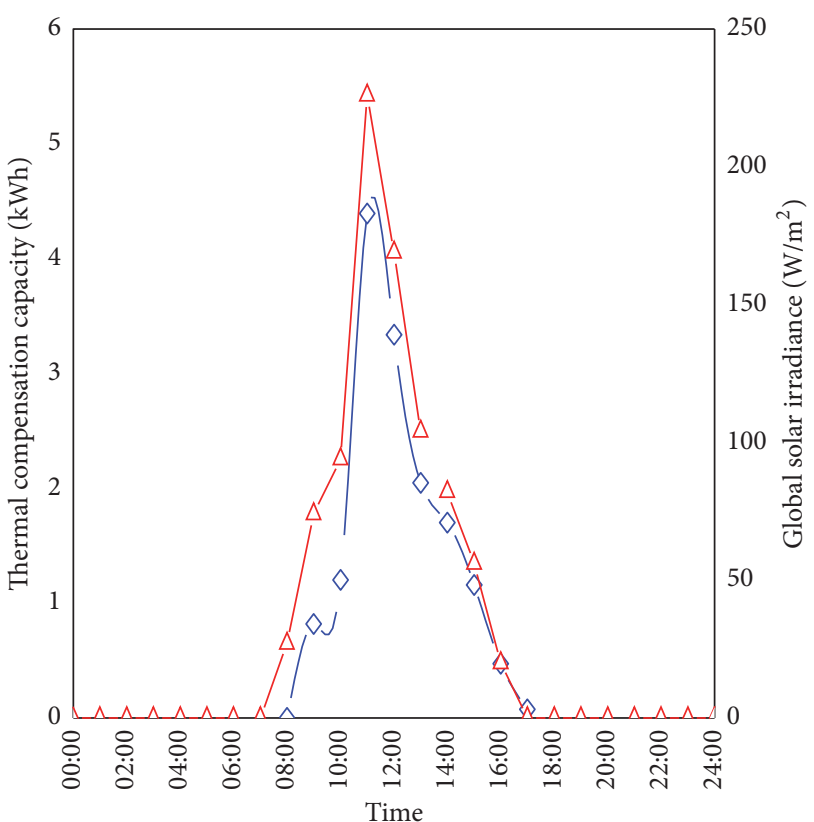

- Thermal compensation capacity
$-\Delta-$ Global solar irradiance

FIGURE 3: Thermal compensation capacity of solar collectors on January 15, 2015.

\subsection{OTC Method}

3.2.1. Principle of OTC Method. At the same circulating water temperature, the thermal compensation capacity of the EAHRU and solar collectors in the ESTC system were mainly determined by the temperature of the exhaust air and the solar irradiance, respectively. As shown in Figures $2-4$, the maximum and minimum values of the exhaust air temperature and solar irradiance appeared at different times. Thus, the peak thermal compensation capacity of the EAHRU and the solar collectors also emerged at different times. Furthermore, the thermal compensation capacity per unit energy consumption of the EAHRU and solar collectors were different in the two systems. Thus, the high-efficiency operating periods of these two systems were also different.

As shown in Figure 4, the extremum of the thermal compensation capacity of EAHRU occurred in the morning and evening when the electrical load of the air conditioning and lighting systems was highest in winter. However, the extremum of the solar radiation intensity and thermal compensation capacity of solar collectors occurred at noon. Therefore, it is necessary to set an appropriate operation schedule for these two systems.

To ensure both systems (and the ESTC as a whole) operate efficiently, we proposed an optimized thermal compensation (OTC) method based on the parameters prediction. Figure 5 shows the flow chart of the OTC method. Based on the weather forecast parameters, predictions of the next day's exhaust air temperature and solar irradiance are primarily needed in the OTC method. These predicted values can subsequently be used to calculate the thermal compensation 


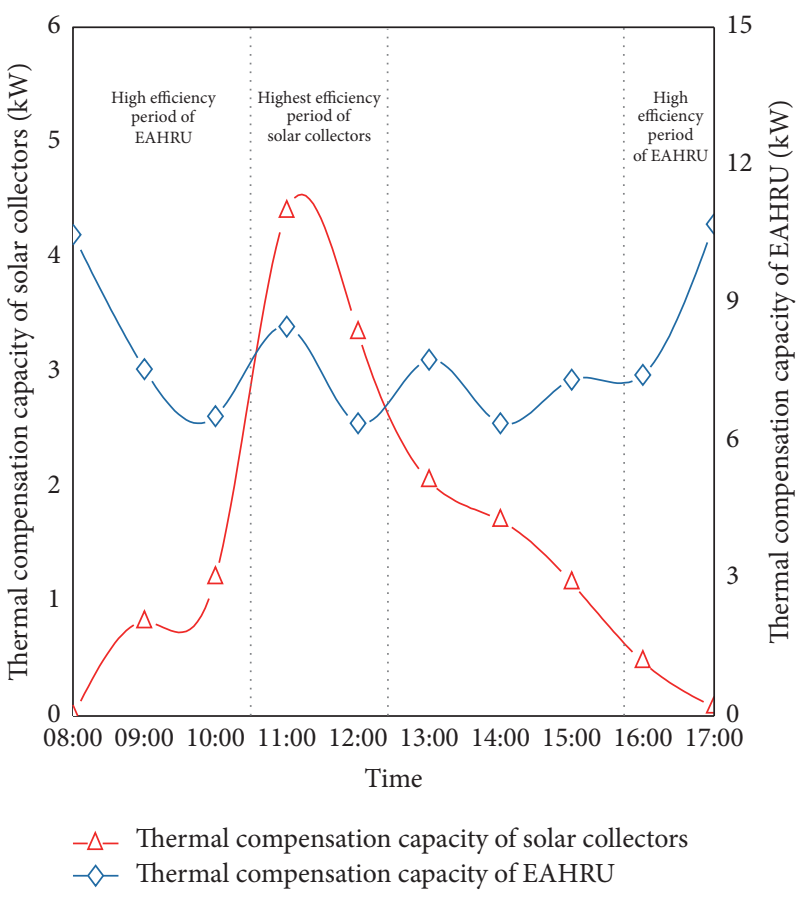

FIGURE 4: Thermal compensation capacity of solar collectors and EAHRU on January 15, 2015.

capacity of the EAHRU and solar collectors. Finally, the highest efficiency period of the EAHRU and solar collectors during the day could be set as the effective working time for the next day's schedule.

The proposed OTC method can be used to improve the thermal compensation efficiency of the EAHRU and solar collectors combined thermal compensation system. For example, during times when the solar radiation intensity is low at dusk, the building's heat gain and thermal compensation efficiency of the solar collectors decrease though the heating load of the building increases. The increasement of heating load then leads to the improvement of the electrical load and the rising of exhaust air temperature of the ETD room. Consequently, the thermal compensation capacity and efficiency of the EAHRU are enhanced with higher inlet air temperature. Under the OTC method, the EAHRU runs during this period while the solar collectors are shut off.

Applying the OTC method, both the EAHRU and the solar thermal systems can operate in the high-efficiency period. However, the method requires accurate prediction of the next day's ETD room exhaust air temperature and solar irradiance. Thus, parameters prediction method is an essential part of the OTC method.

\subsubsection{Parameter Prediction Method}

(1) Prediction of Exhaust Air Temperature. The exhaust air temperature of the ETD room not only is associated with the temperature of the makeup air from outdoors but also has a positive correlation with the equipment heat dissipation of the building's electrical load (including the air conditioning system's electrical load, illumination load, elevator load, office equipment load, and kitchen equipment load).

Thus, we used a modified GM $(1,1)$ model $[36,37]$ based on temperature measurements and weather forecast parameters to predict the next day's hourly dry-bulb temperatures of the ETD room exhaust air. The principles of the modified GM $(1,1)$ model are as follows.

For any given time series data,

$$
X^{(0)}=\left\{X^{(0)}(t)\right\}, \quad t=1,2, \ldots, n .
$$

In this study, the time series data are the hourly dry-bulb temperatures of the ETD room exhaust air. Through the firstorder accumulated generating operation (1-AGO), the regular and smooth new data sequence is obtained from the original data sequence:

$$
X^{(1)}=\left\{X^{(1)}(t)\right\}, \quad t=1,2, \ldots, n,
$$

where

$$
\begin{aligned}
X^{(1)}(k) & =X^{(0)}(1)+X^{(0)}(2)+\cdots+X^{(0)}(k) \\
& =\sum_{j=1}^{k} X^{(0)}(j) .
\end{aligned}
$$

Therefore, the first-order differential equation is established as GM $(1,1)$ :

$$
\frac{d X^{(1)}}{d t}+a X^{(1)}=b
$$

The solution is

$$
\widehat{X}^{(1)}(k+1)=\left[X^{(0)}(1)-\frac{b}{a}\right] e^{-a k}+\frac{b}{a} .
$$

Then, the predicted values for the original data can then be obtained by the inversed accumulated generating operation:

$$
\widehat{X}^{(0)}(k+1)=\widehat{X}^{(1)}(k+1)-\widehat{X}^{(1)}(k) .
$$

To improve the calculation accuracy, we used the following day's three-hourly maximum and minimum temperature forecasts by the China Meteorology Administration to calculate the scale factors for every three-hour period from 00:00 to $24: 00$.

The scale factors of the GM $(1,1)$ model can be defined as

$$
\begin{gathered}
\delta_{h}=\frac{x_{h}-x_{\mathrm{avg}}}{x_{p, \max }-x_{\mathrm{avg}}} \\
\delta_{l}=\frac{x_{\mathrm{avg}}-x_{l}}{x_{\mathrm{avg}}-x_{p, \min }} .
\end{gathered}
$$

The grey model $(\mathrm{GM}(1,1))$ corrected by the forecasted weather data is called the modified grey model (modified GM $(1,1)$ model). The exhaust air's dry-bulb temperature on January 15,2015 , (i.e., a typical working day) was taken as an 


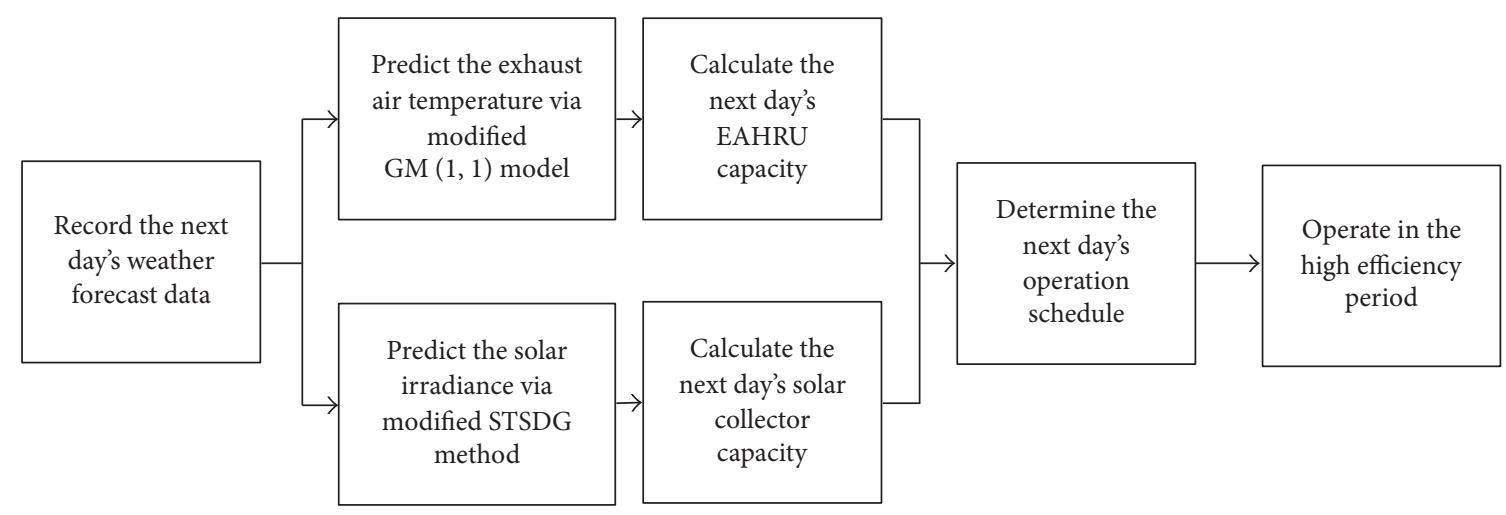

FIGURE 5: Flow chart of the OTC method.

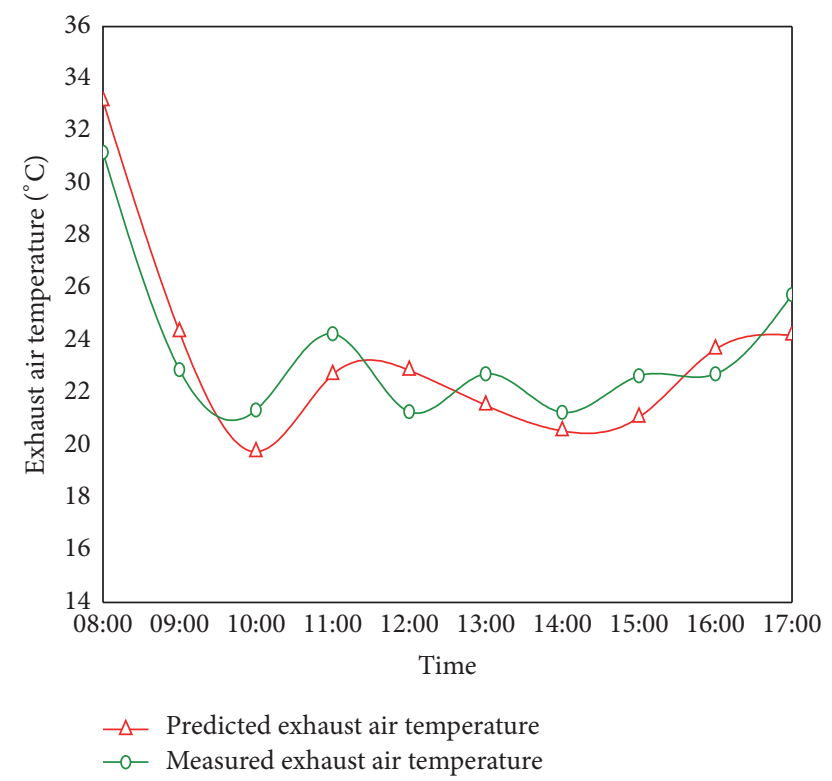

FIGURE 6: Comparison of measured and predicted hourly exhaust air dry-bulb temperature on January 15, 2015.

example. As shown in Figure 6, the curve of the predicted dry-bulb temperature matches that of the measured values; the MAPE of the hourly dry-bulb temperature for nine hours of this typical day was $6.41 \%$, which is acceptable.

(2) Prediction of the Next Day's Hourly Solar Irradiance. The "solar term similar days group" (STSDG) method [38], a solar irradiance prediction method that utilizes DeST meteorological library and weather forecast parameters as inputs, was applied here for hourly solar irradiance correction. MARKOV chain and Collares-Pereira and Rabl model were used to calculate the hourly total solar irradiance of the DeST meteorological library [39]. The direct and diffuse radiations were calculated by using Liu and Jordan model [40].

The 360-degree solar celestial longitude was divided into 24 equal parts of 15 degrees each, as a solar term, by ancient Chinese scholars. We subdivided a whole year into 72 equal parts of 5 degrees each, each with a duration of 5 to 6 days.
A "solar term similar days group" (STSDG) was defined for the 5 to 6 day periods with similar solar irradiance and meteorological conditions [38]. As an example, the similar days group subdivision period from January 6 to February 18 is shown in Table 2.

Assuming that atmospheric pollution influence is ignored in the STSDG method, the relation between total solar irradiance and a given period of solar irradiance outside the atmosphere is associated with cloud amount (the volume of cloud). Clearness index $K t$ can be used to measure the cloud amount degree [41-45]. Clearness index $\left(K t=H / H_{0}\right)$ is the ratio of the total horizontal solar radiance $H$ on the earth to the solar irradiance of $H_{0}$ extraterrestrial [46].

It is worth noting that, due to the good air quality during the summer in Beijing [47], the decay in forecast accuracy caused by air pollution is negligible when the STSDG method is used during the summer months. However, the impact of air pollution on solar irradiance prediction accuracy must be taken into account in certain regions (some large metropolitan areas such as Beijing and New Delhi) during the winter, due to the high frequency of severe air pollutants in these regions in recent years [48].

Qi et al. [49] provided a meaningful discussion on air pollution as an important factor affecting the surface total solar irradiance in China. Based on three years of observational data published by the National Weather Service and National Environmental Quality Inspection Station, Wang et al. [50] identified a regressive relation between air quality index (AQI) and global solar irradiance under sunny weather condition. Tao et al. [51] found that the AQI has a significant influence on global solar irradiance when the cloud amount is low ( $\mathrm{CL}<0.3$ ), but, under higher cloud amount or in foggy weather, the AQI has negligible influence when the solar irradiance is mainly reduced by cloud or fog. Based on previous studies, this manuscript adopted a modified STSDG method in which the maximum hourly global solar irradiance in low cloud days $(\mathrm{CL}<0.3)$ predicted by the normal STSDG method is corrected using an AQI correction factor calculated based on [51]. Figure 7 shows the correction factor of global solar irradiance based on AQI. The corresponding weather conditions of low cloudy day $(\mathrm{CL}<0.3)$ in weather forecasting are sunny or sunny with haze. 
TABLE 2: The similar days group subdivision based on 24 solar terms of ancient China.

\begin{tabular}{|c|c|c|c|c|c|}
\hline Solar term & $\begin{array}{c}\text { Sequence of similar } \\
\text { days group }\end{array}$ & Date & Number of days & $\begin{array}{c}\text { Sequence number } \\
\text { of days }(n)\end{array}$ & $\begin{array}{c}\text { Solar celestial } \\
\text { longitude }\end{array}$ \\
\hline \multirow{3}{*}{$\begin{array}{l}\text { Slight cold (23rd solar } \\
\text { term) }\end{array}$} & $\mathrm{XH}-1$ & Jan. 6 Jan. 10 & 5 & $3 \sim 7$ & $285-290$ \\
\hline & $\mathrm{XH}-2$ & Jan. 11 Jan. 15 & 5 & $8 \sim 12$ & $290-295$ \\
\hline & $\mathrm{XH}-3$ & Jan. 16 Jan. 20 & 5 & $13 \sim 17$ & $295-300$ \\
\hline \multirow{3}{*}{$\begin{array}{l}\text { Great cold ( } 24 \text { th solar } \\
\text { term) }\end{array}$} & DH-1 & Jan. 21 Jan. 25 & 5 & $18 \sim 22$ & $300-305$ \\
\hline & $\mathrm{DH}-2$ & Jan. 26 Jan. 30 & 5 & $23 \sim 27$ & $305-310$ \\
\hline & DH-3 & Jan. 31 Feb. 3 & 4 & $28 \sim 31$ & $310-315$ \\
\hline \multirow{3}{*}{$\begin{array}{l}\text { Spring begins (1st solar } \\
\text { term) }\end{array}$} & LC-1 & Feb. $4 \sim$ Feb. 8 & 5 & $32 \sim 36$ & $315-320$ \\
\hline & LC-2 & Feb. 9 Feb. 13 & 5 & $37 \sim 41$ & $320-325$ \\
\hline & LC-3 & Feb. $14 \sim$ Feb. 18 & 5 & $42 \sim 46$ & $325-330$ \\
\hline
\end{tabular}

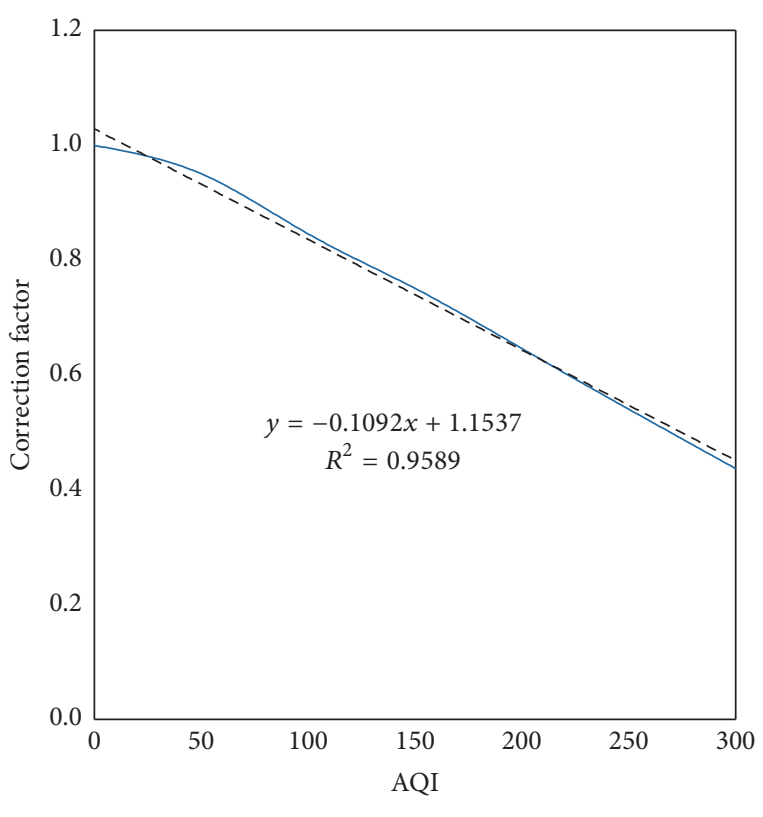

_ Global solar irradiance

FIGURE 7: Correction factor of global solar irradiance based on AQI.

Also, due to the severe air pollution condition, the Meteorology Administration in Beijing has integrated air quality forecast with the weather forecast during winter months. When the weather condition is cloudy and the air pollution degree exceeds "mild" levels (AQI > 100), the weather conditions in Beijing are officially described as "hazy." The air pollution forecast based on AQI according to the air quality index code [52] is also provided at the same time. Table 3 gives the relations between clearness index, weather, air quantity forecast, and the solar irradiance of Beijing in the similar days group (XH-2) according to the traditional STSDG method. Two kinds of new possible weather conditions, which are haze with severe or heavy pollution $(A Q I>200)$ and haze with medium or mild pollution $(200>$ AQI $>100)$, were added in this table to take advantage of the upgraded weather forecast.

Table 4 shows the process using modified STSDG method to forecast solar irradiance in similar days. Due to the

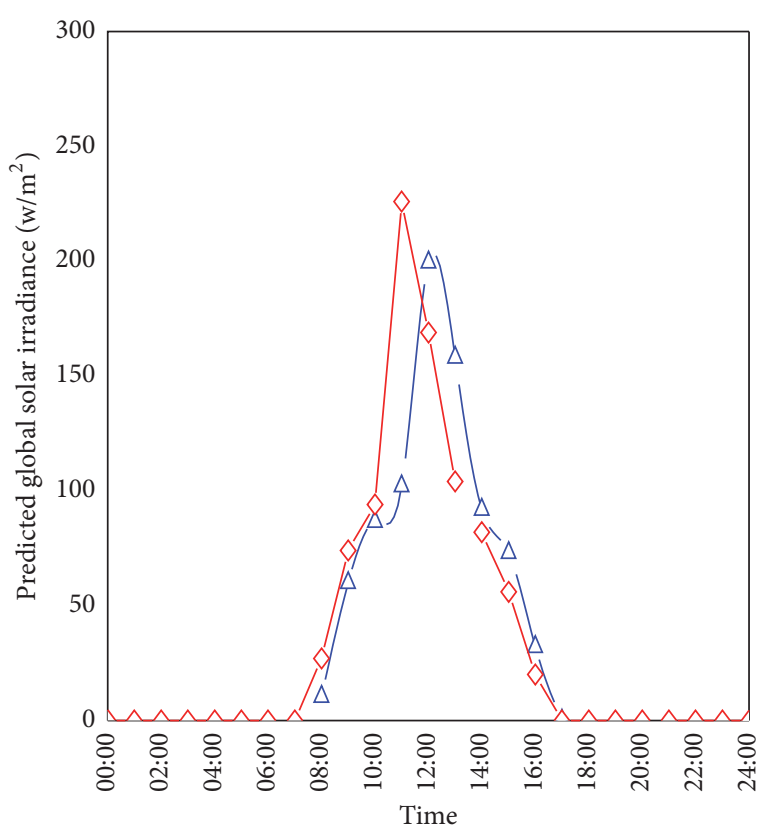

$-\triangle$ - Predicted global solar irradiance

$\checkmark$ Measured global solar irradiance

Figure 8: Comparison of measured and predicted hourly solar irradiance of Beijing on January 15, 2015.

randomness of instantaneous meteorological conditions and other factors, the MAPE of maximum global solar irradiance obtained via STSDG method was $18.26 \%$, which is close to that obtained via traditional prediction methodology [53].

In the buildings that utilize solar energy systems in winter to compensate heat for underground heat exchangers, it is necessary to calculate the accumulated quantity of heat gain by solar collectors to determine the total heat compensation quantity rather than to calculate the transient heat gain. Thus, during solar irradiance prediction, it is very important to obtain accurate accumulated solar irradiance during highefficiency periods. Figure 8 is the comparison of the predicted and measured hourly global solar irradiance on a typical day. The absolute percentage error (APE) of the predicted hourly global solar irradiance was relatively high, averaging 
TABLE 3: Range of hourly total solar irradiance $R_{R}$ corresponding to $K_{t}$ in XH-2 similar days group.

\begin{tabular}{|c|c|c|c|c|c|}
\hline$K_{t}$ range & $\begin{array}{c}\text { Serial number of } \\
\text { cleanness index range }\end{array}$ & $\begin{array}{l}\text { Possible weather } \\
\text { conditions }\end{array}$ & $\begin{array}{l}\text { Total solar } \\
\text { irradiance range } \\
R_{R}\left(\mathrm{w} / \mathrm{m}^{2}\right)\end{array}$ & $\begin{array}{c}\text { The maximal hourly } \\
\text { total solar irradiance } \\
\text { range } R_{R} \text { in } \\
\text { DS- } 1\left(\mathrm{w} / \mathrm{m}^{2}\right)\end{array}$ & Data sources \\
\hline $0 \sim 0.15$ & KT1 & $\begin{array}{l}\text { Overcast but may } \\
\text { transform to rain } \\
\text { and } \\
\text { Haze (severe or } \\
\text { heavy pollution) }\end{array}$ & $20.5 \sim 81.3$ & 24.87 & Dest 1.14 \\
\hline $0.15 \sim 0.28$ & KT 2 & $\begin{array}{l}\text { Overcast and will } \\
\text { not transform to } \\
\text { rain }\end{array}$ & $81.3 \sim 162.5$ & 115.6 & Dest 1.13 \\
\hline \multirow{9}{*}{$0.28 \sim 0.5$} & \multirow{9}{*}{ KT 3} & \multirow{9}{*}{$\begin{array}{l}\text { Weather transform } \\
\text { between cloudy } \\
\text { and overcast }\end{array}$} & \multirow{9}{*}{$162.5 \sim 421.0$} & 407 & 2012.1.15 \\
\hline & & & & 290 & 2013.1.12 \\
\hline & & & & 191 & 2013.1.13 \\
\hline & & & & 375 & 2013.1.14 \\
\hline & & & & 338 & 2013.1.15 \\
\hline & & & & 169.94 & Dest 1.12 \\
\hline & & & & 319.34 & Dest 1.15 \\
\hline & & & & 345.95 & Dest 1.16 \\
\hline & & & & 304.5 & Dest 1.10 \\
\hline \multirow{8}{*}{$0.5 \sim 0.74$} & \multirow{8}{*}{ KT 4} & \multirow{8}{*}{$\begin{array}{l}\text { Weather transform } \\
\text { between cloudy } \\
\text { and sunny, haze } \\
\text { (medium or mild } \\
\text { pollution) }\end{array}$} & \multirow{8}{*}{$421.0 \sim 806.8$} & 610 & 2012.1 .12 \\
\hline & & & & 715 & 2012.1.13 \\
\hline & & & & 804 & 2012.1.14 \\
\hline & & & & 787 & 2014.1.12 \\
\hline & & & & 642 & 2014.1.13 \\
\hline & & & & 627 & 2014.1.14 \\
\hline & & & & 723 & 2014.1.15 \\
\hline & & & & 701.1 & 2014.1.15 \\
\hline $0.74 \sim 1$ & KT 5 & $\begin{array}{c}\text { Sunny and sunny } \\
\text { with hazy }\end{array}$ & $806.8 \sim 1176.3$ & 809 & 2012.1.14 \\
\hline
\end{tabular}

18.5\%. However, the APE between the predicted and measured values of accumulated daily solar irradiance was only $4.7 \%$. In the four time points with the highest global solar irradiance (11:00 to 14:00), the APE between the accumulated measured value and accumulated forecasted value of global solar radiation was only $8.60 \%$ in the typical day. The results were similar for other days. Consequently, although using the modified STSDG method to predict hourly solar irradiance is not quite sufficiently accurate, the results do have good accuracy regarding accumulated solar irradiance.

\section{Experiment of ESTC}

To evaluate the performance of the ESTC-GSHP system and OTC method, an office building installed with an ESTCGSHP system was chosen as the research object in this study, and a one-year experimental operation was conducted.

4.1. Research Object. The air conditioning system in the building examined here was designed with zonal cooling and heating to adapt to the operational demands of the
ESTC system. The selected experimental zone for ESTC has a simulated maximum cooling load of $139.8 \mathrm{~kW}$ and a simulated maximum heating load of $151.2 \mathrm{~kW}$. The building has an ETD room equipped with two $630 \mathrm{kVA}$ transformers which deliver service to the office building and several nearby buildings. A mechanical exhaust system was adopted to remove heat released by the equipment. The heating load of the construction zone served by EAHRU ( $\left.Q_{\text {EAHRU }}\right)$ was $98.7 \mathrm{~kW}$ by our calculations based on (1), which accounted for $65.3 \%$ of the total heating load of the building. Combined with the solar collectors, $100 \%$ of the ground heat exchanger could be thermally compensated for by the ESTC system in this building. In other buildings with relatively smaller ETD room or larger heating load, more solar collectors can be applied to ensure the sufficient quantity of thermal compensation.

4.2. Experimental Method. A one-year operating test was conducted from January 12, 2015, to January 12, 2016, in the office building described above. The transition season was defined as the period between September 20 and November 


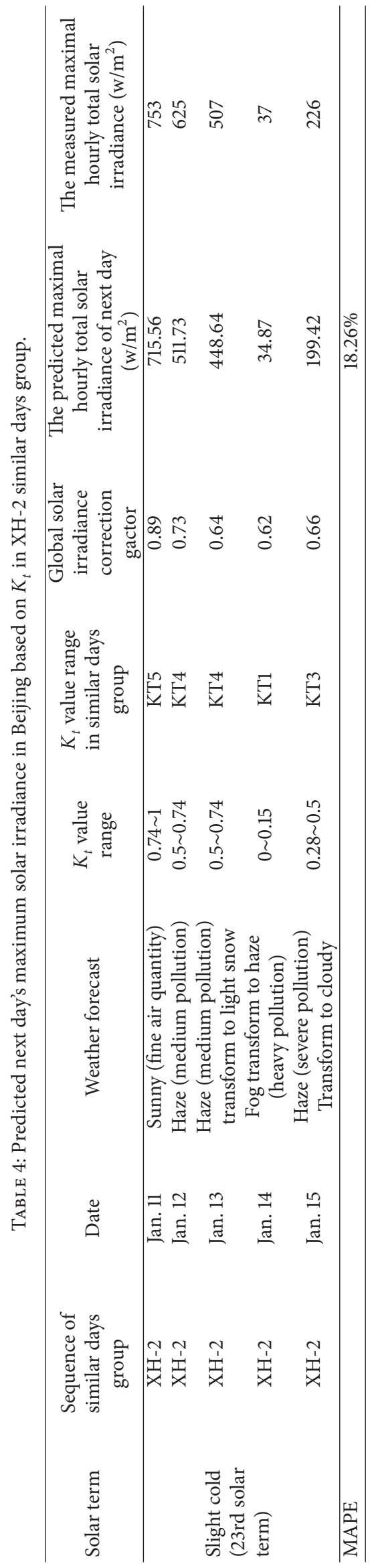


TABLE 5: Operation schedules of the two kinds of thermal compensation system on January 15.

\begin{tabular}{|c|c|c|c|c|c|c|c|}
\hline \multirow{2}{*}{ System } & \multicolumn{7}{|c|}{ Time } \\
\hline & $7: 30 \sim 9: 30$ & 9:30 10:30 & 10:30 11:30 & $11: 30 \sim 12: 30$ & $12: 30 \sim 13: 30$ & $13: 30 \sim 14: 30$ & $14: 30 \sim 17: 30$ \\
\hline EAHRU & $\sqrt{ }$ & - & - & - & - & - & $\sqrt{ }$ \\
\hline Solar collectors & - & - & - & $\sqrt{ }$ & - & - & - \\
\hline EAHRU plus Solar collectors & - & - & $\sqrt{ }$ & - & $\sqrt{ }$ & $\sqrt{ }$ & - \\
\hline
\end{tabular}

14 and the heating season between November 15 and March 15 of the following year. To minimize the effect of thermal compensation on the cooling efficiency in summer, the ESTC-GCHP system was put into service in autumn and winter and taken out of service in spring and summer.

An automatic control system was employed to control and monitor the heat pump unit, the ground heat exchanger circulating pump, the heating circulating pump, and various electrically operated water valves and air valves, as well as to measure and record the water inlet/outlet temperatures of the condenser and evaporator of the heat pump unit. The supply and return water temperatures and heat exchange quantity of the ground heat exchanger were measured by a set of thermal meters on the main supply and return water pipelines. Seven PT1000 temperature sensors installed in the measuring well at intervals $10 \mathrm{~m}$ from the ground surface in the ground heat exchanger zone measured the underground rock-soil mass temperature; the average of the seven measured temperatures was considered the formation temperature of the underground rock-soil mass.

4.3. Optimal Operation. Both compensation systems functioned with better performance after they were optimized through OTC method. Thus, OTC method owns large potentials for both improving the efficiency and reducing the energy consumption of thermal compensation. The operation schedules of both thermal compensation systems on January 15, 2015, are shown in Table 5. The system began to operate at 7:30 am, half an hour before the working time. As shown in Table 5 and Figure 4, the EAHRU and solar collectors were set to work at their high-efficiency periods according to the thermal compensation capacities, which were calculated based on the predicted exhaust air temperature and solar irradiance.

\section{Results and Analysis}

5.1. Evaluation Index. The following indexes were defined to evaluate and analyze the performance of the ESTC-GCHP system.

5.1.1. Thermal Compensation Per Unit Energy Consumption (TEC). TEC was defined as the ratio of the thermal compensation quantity $\left(P_{c}\right)$ to the power consumption during the thermal compensation process $\left(P_{i}\right)$ :

$$
\mathrm{TEC}=\frac{P_{c}}{P_{i}} .
$$

TABLE 6: Components used in TRNSYS simulation.

\begin{tabular}{|c|c|}
\hline Weather data & Type $15-3$. \\
\hline Cooling and heating load & $\begin{array}{l}\text { Type 9e (Read load files generated by } \\
\text { EnergyPlus) }\end{array}$ \\
\hline EAHRU & Equation component \\
\hline Solar collectors & Type $1 b$ \\
\hline Closed water mixing tank & Type 60b \\
\hline Ground heat exchanger & Type 557a \\
\hline Heat pump & Type 668 \\
\hline Circulation pumps & Type 110 \\
\hline Valves & Type 647 and type 649 \\
\hline Fans & Type 3a \\
\hline Load terminal & Type 682 \\
\hline Simulation output & Type 65 and type 25 \\
\hline Controllers & $\begin{array}{l}\text { Type } 14 \mathrm{~h} \text {, type } 14 \mathrm{l} \text {, type } 14 \mathrm{k} \text {, and the } \\
\text { Equation component }\end{array}$ \\
\hline
\end{tabular}

The higher the efficiency of the thermal compensation system, the greater the TEC value.

5.1.2. Correlation Coefficient. The correlation coefficient $(R)$ is used to evaluate the linear correlation between the solar irradiance and AQI [54]:

$$
r=\frac{\sum_{i=1}^{n}\left(X_{i}-\bar{X}\right)\left(Y_{i}-\bar{Y}\right)}{\sqrt{\sum_{i=1}^{n}\left(X_{i}-\bar{X}\right)^{2}} \sqrt{\sum_{i=1}^{n}\left(Y_{i}-\bar{Y}\right)^{2}}},
$$

where $X$ and $Y$ are two groups of different variables.

5.1.3. Thermal Imbalance Ratio (TIR). TIR was defined to assess the thermal imbalance level of the ground heat exchanger:

$$
\mathrm{TIR}=\frac{Q_{\mathrm{AHR}}-Q_{\mathrm{AHE}}}{\max \left(Q_{\mathrm{AHR}}, Q_{\mathrm{AHE}}\right)} \times 100 \%,
$$

where $Q_{\mathrm{AHR}}$ is the annual accumulated heat rejected into underground during the cooling season and $Q_{\mathrm{AHE}}$ is the annual accumulated heat extracted from underground during the heating season [55].

5.2. Underground Thermal Balance Analysis. The performance of the ESTC-GCHP system in the office building was simulated by using TRNSYS. A traditional GCHP system with the same capacity was also simulated. The TRNSYS types used in this study were listed in Table 6. 
Figure 9 illustrates the TIR of GCHP and ESTC-GCHP in 10 years. As shown in Figure 9, the normal GCHP system's TIR was higher, the annual average value was $-21.23 \%$, and the peak was $-34.8 \%$ in the first year. By contrast, the TIR of the ESTC-GCHP system showed no significant change over 10 years of operation and was smaller than $2.50 \%$ all the time. The average value of TIR in 10 years was $1.78 \%$, and the calculated TIR based on experimental data in the first year was $2.16 \%$. These results indicate that the ESTCGCHP system is a feasible and effective approach to resolving underground thermal imbalance.

5.3. Soil Temperature. The simulated average annual soil temperatures of the GCHP and the ESTC-GCHP systems are presented in Figure 10. As shown in Figure 10, the average soil temperature of the GCHP system dropped from $16.63^{\circ} \mathrm{C}$ to $13.01^{\circ} \mathrm{C}$, while the mean annual temperature declined $0.36^{\circ} \mathrm{C}$ during the 10 -year operation period. However, the underground temperature of the ESTC-GCHP system was relatively more stable overall, with a drop of only $0.11^{\circ} \mathrm{C}$ (from $16.13^{\circ} \mathrm{C}$ to $16.02^{\circ} \mathrm{C}$ ) over the 10 -year period, since the heat extracted from soil was approximately equal to the rejected heat. These results show that the ESTC-GCHP system can compensate for heat losses to the ground heat exchanger and could be used to efficiently eliminate the continuous decline of underground temperatures.

Due to the large thermal inertia of soil, short transient parameters cannot reflect the heat balance of the ground heat exchanger. Thus, the weekly average temperature was adopted to represent the thermal balance conditions of the soil on a yearly basis. As shown in Figure 11, during the first year of the operational test, the week-round soil average temperature for the first week was found to be $16.62^{\circ} \mathrm{C}$. The mean soil temperature of the last week was $15.89^{\circ} \mathrm{C}$, which decreased to $0.73^{\circ} \mathrm{C}$ in a year. The measured soil average temperature of the ESTC-GCHP system in the first week was $16.81^{\circ} \mathrm{C}$, while it was $17.57^{\circ} \mathrm{C}$ in the last week. In other words, the soil temperature slightly increased instead of decreasing, indicating that the rejected thermal quantity already exceeded the extracted thermal quantity of the ESTC-GCHP system.

5.4. Prediction Results of Exhaust Air Temperature of ETD Room. Office buildings and other large commercial buildings provide better conditions for the prediction of electric load and other related parameters due to standardized property management and routine work hours. Thirty-one days (January 12 to February 11,2015) were taken as a typical month. Figure 12 shows the low and slowly decreasing APE of the predicted ETD's exhaust air temperature determined by using modified GM $(1,1)$ model in the typical month; the monthly MAPE was $4.26 \%$.

The historical data input to the modified grey model in the early days of the operation period were collected during the trial operation; thus the APE of early days was high. However, the accuracy of the forecasting model was improved along with the accumulation of historical data during the official operation period. Thus, the modified grey model could accurately forecast the exhaust temperature of the

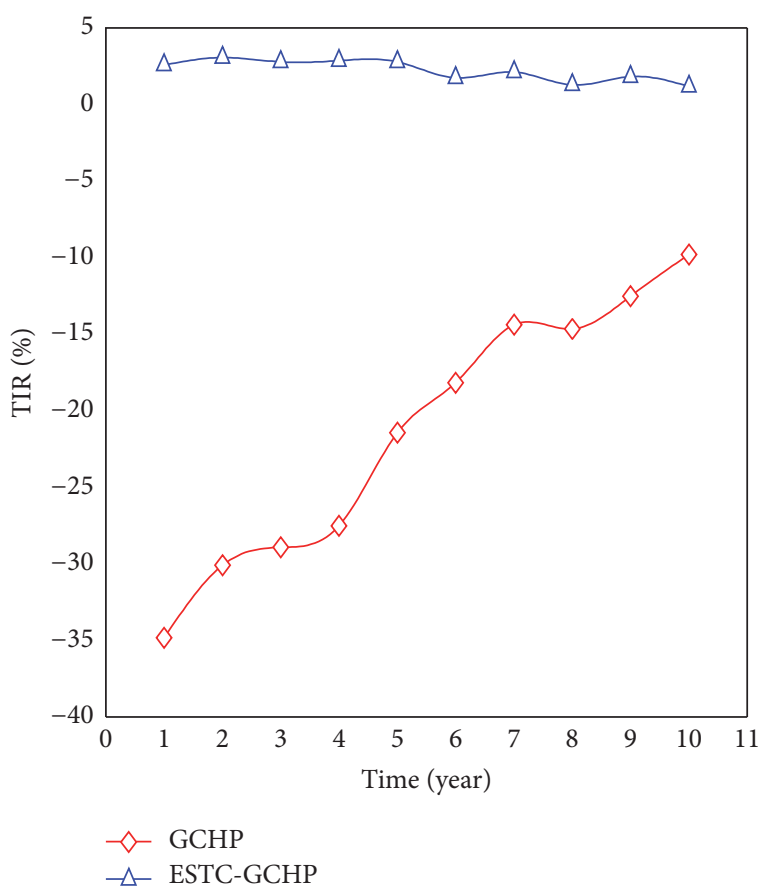

FIgURE 9: Thermal imbalance rates of GCHP and ESTC-GCHP.

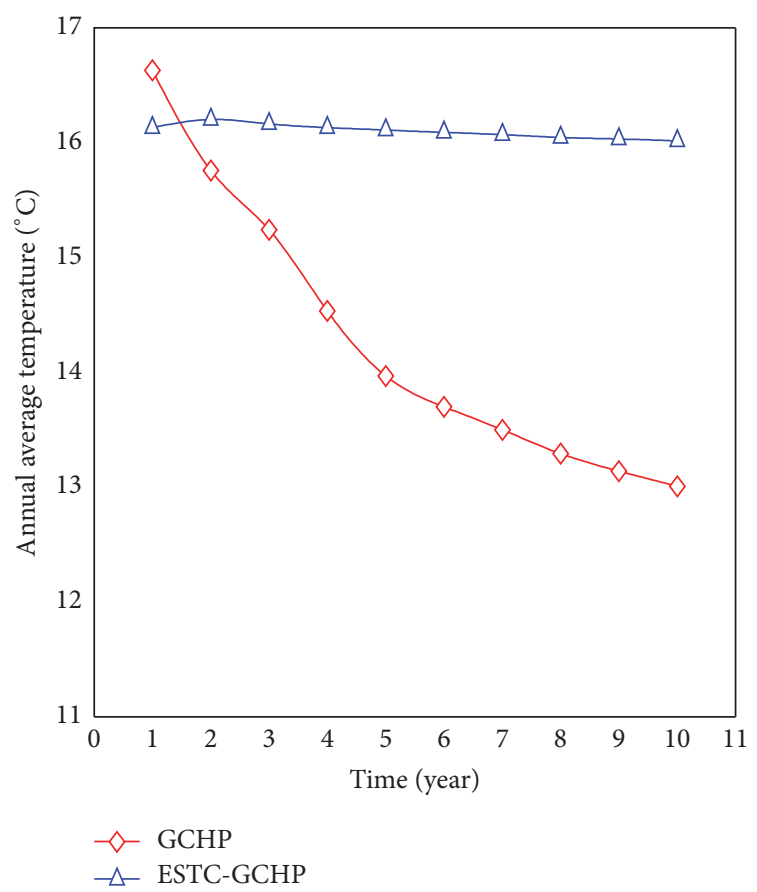

FIGURE 10: Simulated yearly average simulated soil temperature of GCHP and ESTC-GCHP.

ETD room. Moreover, the MAPE between the calculated and measured values of thermal compensation quantity, $8.1 \%$, was within an acceptable range. Additionally, the MAPE between the calculated and the measured values of cumulative thermal compensation quantity was $6.9 \%$. Therefore, the prediction 


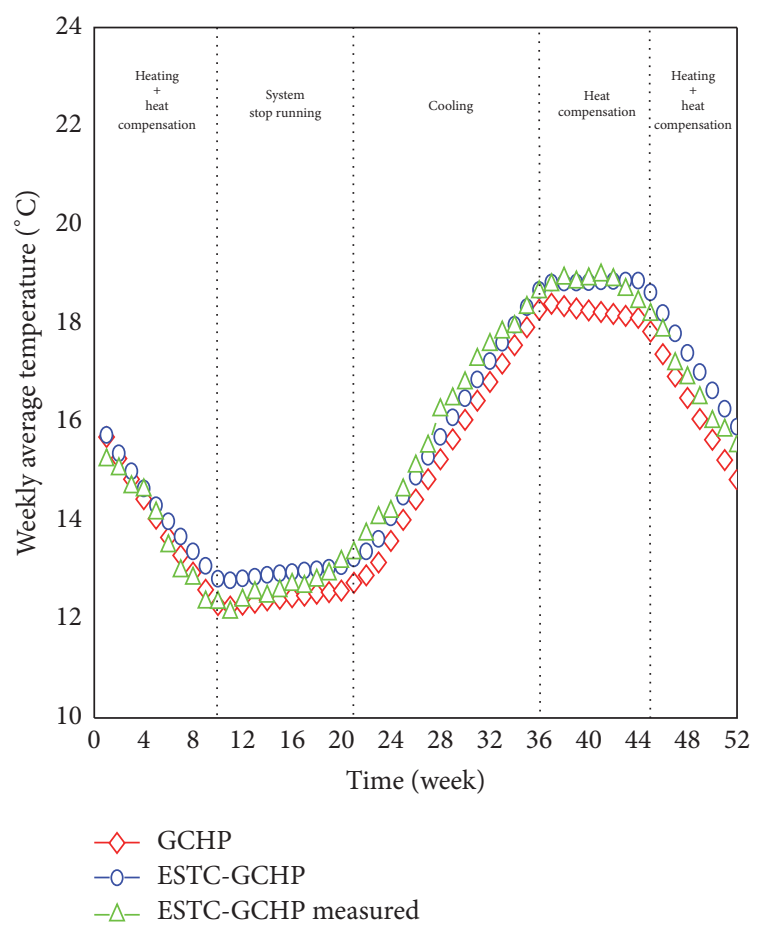

FIGURE 11: Simulated and measured weekly average soil temperature.

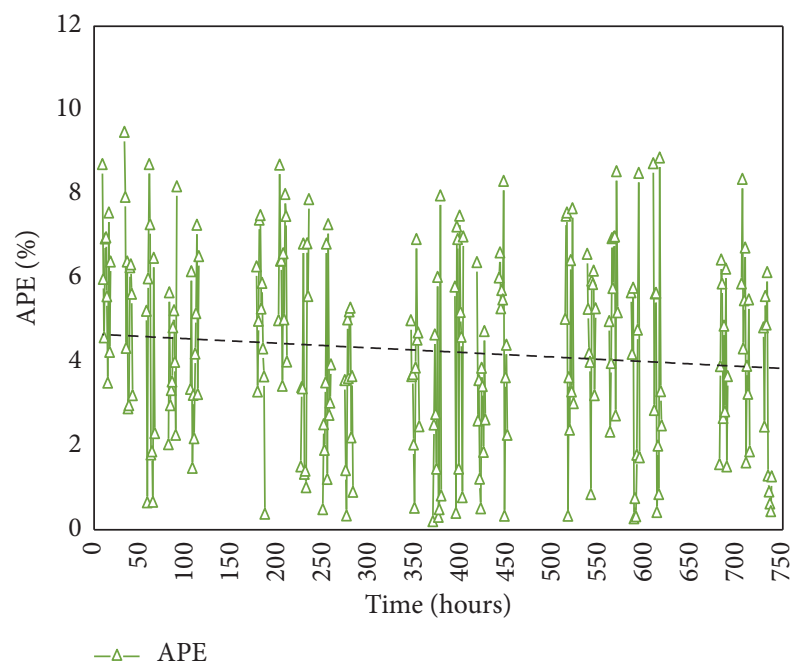

FIGURE 12: APE between measured and predicted hourly exhaust air temperature in Beijing (typical month).

accuracy was satisfactory for the planning of the next day's system operation schedule.

5.5. Prediction Results of Solar Irradiance. A comparison of the next day's predicted and measured global solar irradiance over a typical month is shown in Figure 13. The daily variation trend of these two values was coincident, but not without error. The MAPE between the measured global solar irradiance and the global solar irradiance predicted via modified STSDG method was $11.19 \%$ for a typical winter

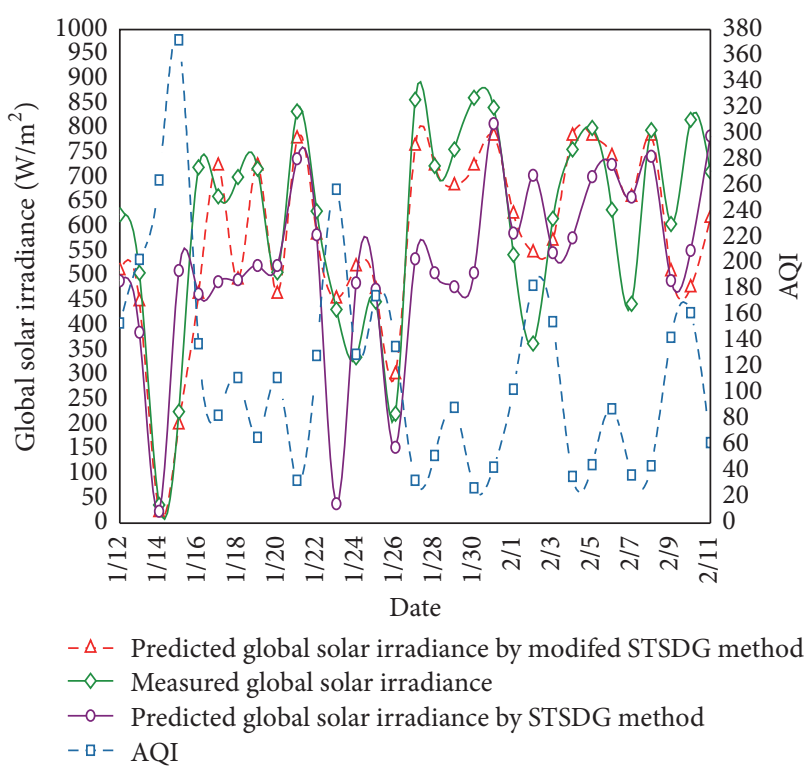

FIGURE 13: Comparison of measured and predicted daily max solar irradiance in Beijing (January 12-February 11, 2015).

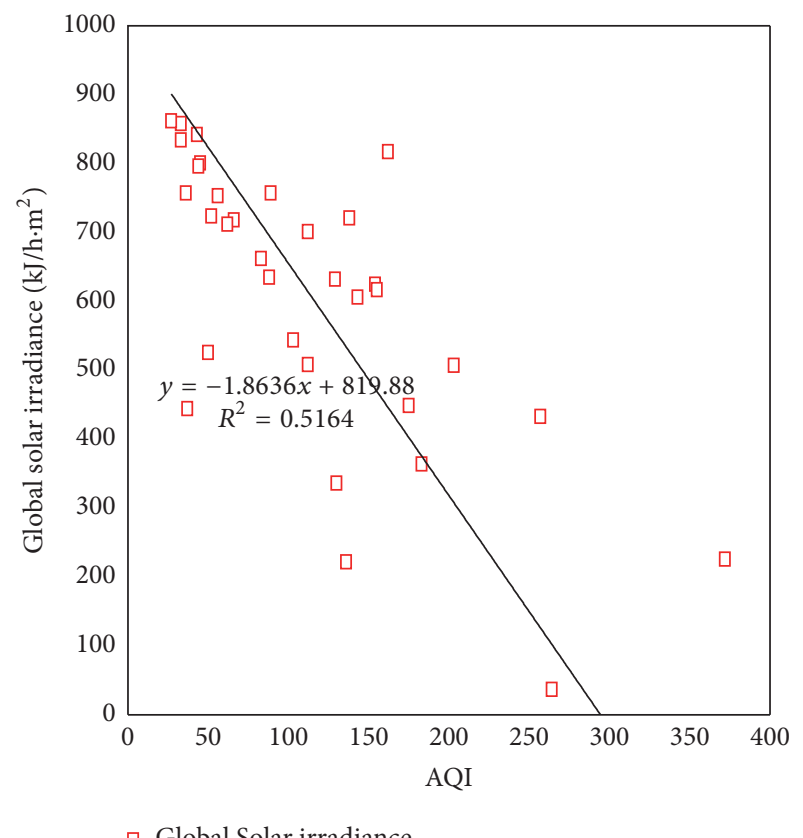

FIGURE 14: Correlation analysis between measured daily max AQI and max solar irradiance in Beijing (January 12-February 11, 2015).

month but was $26.71 \%$ according to the traditional STSDG model.

As shown in Figure 14, in the typical month, a high negative correlation between the extremum of AQI and the maximum of global solar irradiance was found through the analysis of measured values. The maximum of solar irradiance decreased as AQI increased. $R^{2}$ of the linear correlation between these two parameters was 0.516 , and the correlation coefficient $(R)$ was -0.719 . 


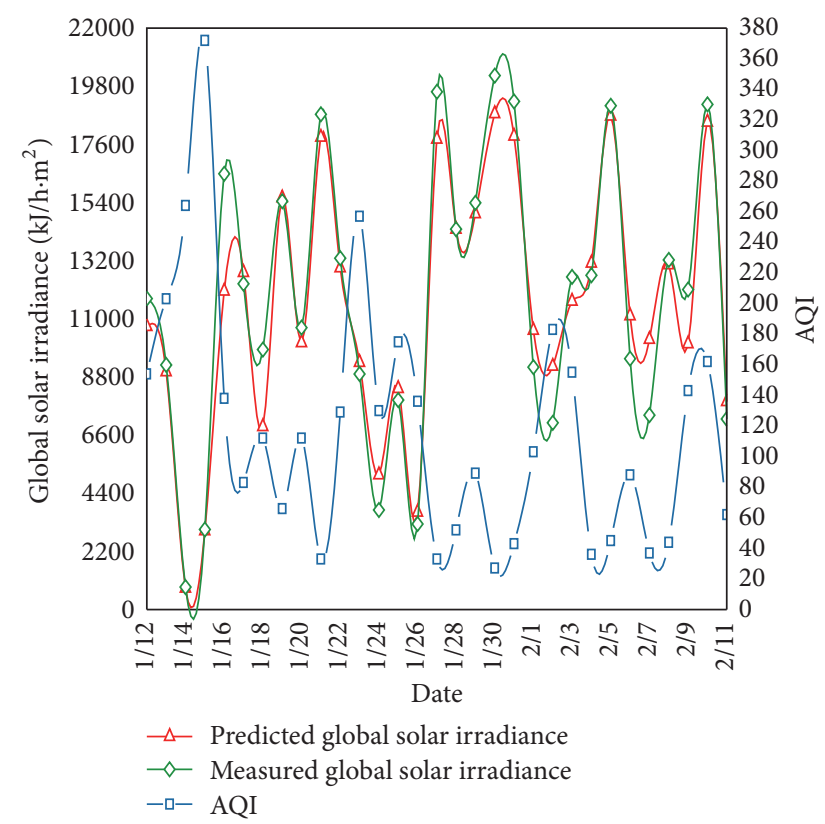

FIGURE 15: Comparison of measured and predicted daily accumulated solar irradiance in Beijing (January 12-February 11, 2015).

Additionally, Figure 15 shows that the measured daily accumulated global solar irradiance of a typical month was highly correlated with daily max value of AQI. The correlation coefficient $(R)$ between these two parameters was -0.616 . The predicted daily accumulated global solar irradiance determined via modified STSDG method exhibited higher accuracy; the MAPE between the predicted and measured values was $8.23 \%$ for a typical month. Furthermore, as shown in Figure 16, the accumulated global solar irradiance of the four-hour period with the highest radiation was more accurately predicted; the monthly MAPE was $6.35 \%$. The correlation coefficient $(R)$ with AQI was -0.530 .

Since there is high correlation in winter between the maximum global solar irradiance and AQI, it is crucial to include the AQI correction factor in the modified STSDG method to improve the prediction accuracy of global solar irradiance during polluted weather conditions. The comparison results indicated that the modified STSDG method has better prediction accuracy than the traditional STSDG method.

Moreover, as shown in Figure 17, $R^{2}$ of the linear correlation between the measured daily extreme values of AQI and solar irradiance was 0.2197 for the whole year, much lower than $R^{2}$ value for a typical winter month. The correlation coefficient $(R)$ for the year was -0.469 , which was also much lower than that in the typical month. These results indicated insignificant correlation between these two extreme values over a one-year period, since the air quality in Beijing is much better in spring and summer than in autumn and winter.

Figures 18 and 19 demonstrate that the predicted heatcollecting capacities by solar collectors were close to the measured values and were highly negatively correlated with AQI over the typical month we assessed. The MAPE between

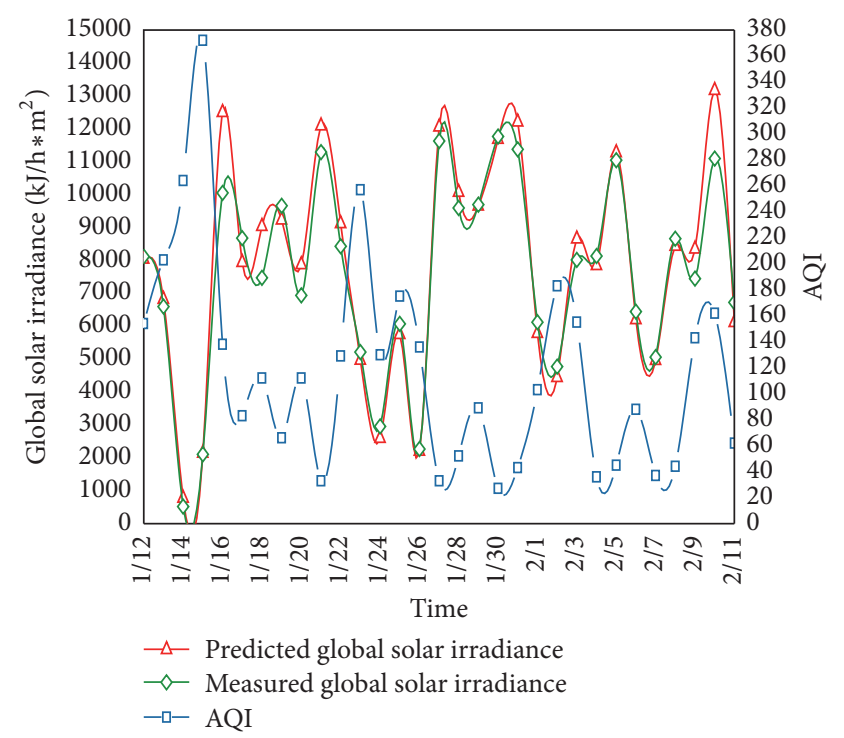

FIGURE 16: Comparison of measured and predicted daily accumulated solar irradiance of top four hours in Beijing (January 12February 11, 2015).

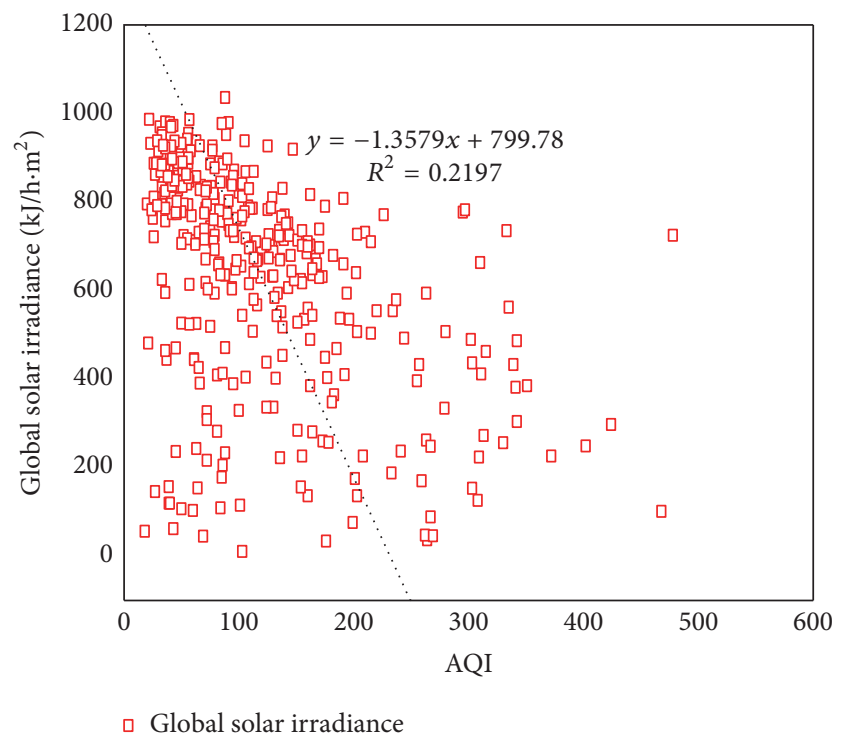

FIGURE 17: Correlation analysis between daily max AQI and max solar irradiance in Beijing (January 12, 2015-January 12, 2016).

the predicted daily maximum heat-collecting capacities and the measured extremums was $13.15 \%$. Moreover, in regard to the accumulated values of the four highest radiation hours, the MAPE was as low as $7.63 \%$.

5.6. Comparison between Conventional Strategy and OTC Method. An operation experiment of thermal compensation system was conducted in the office building for a whole year, from January 12, 2105, to January 12, 2016. In this experiment, the OTC method was adopted to determine the operation schedules for the EAHRU and solar collectors. Using January 15, 2015, as an example day, as shown in 


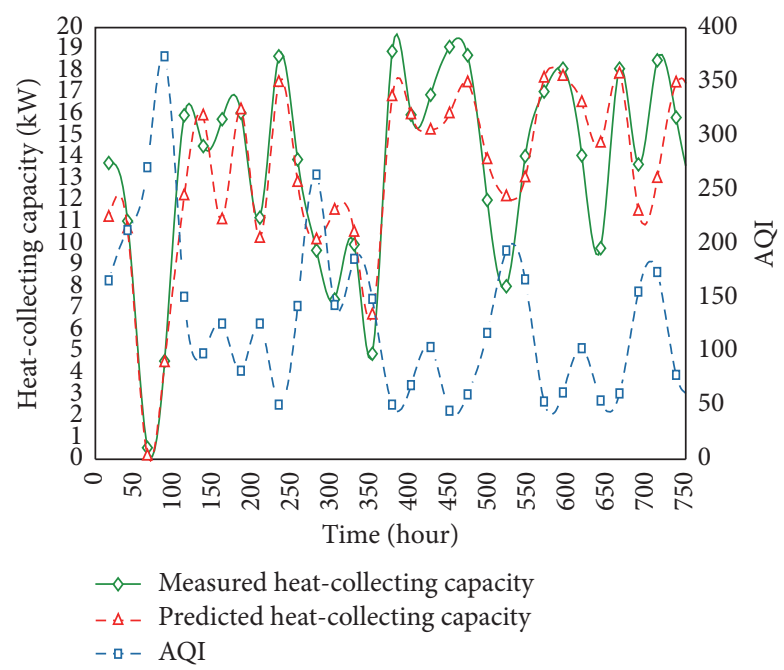

FIGURE 18: Daily maximum heat-collecting capacity of solar collectors in a typical month.

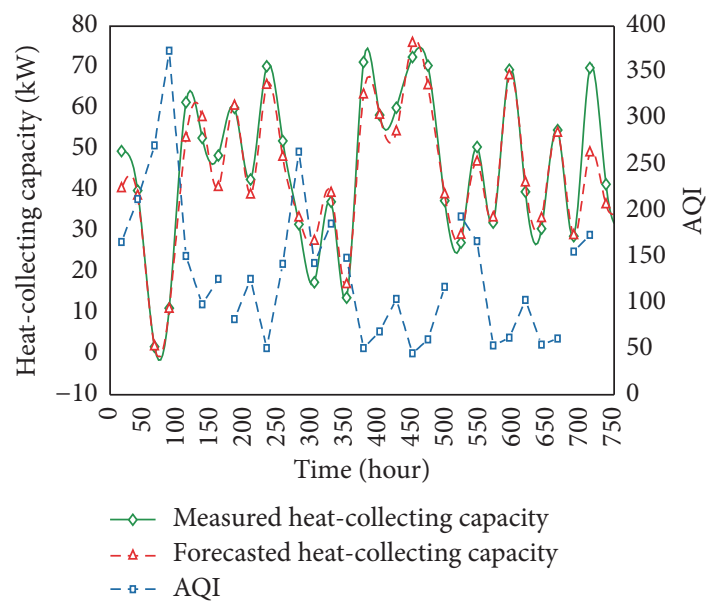

FIGURE 19: Accumulated heat-collecting capacity of the four highest radiation hours in a typical month.

Figure 4 and Table 5, the EAHRU was set to work during the high exhaust air temperature period, while the solar collectors can work during the high solar irradiance period in OTC operation mode. As shown in Figures 20 and 21, the OTC operation mode fully took advantage of the high-efficiency period of the EAHRU and solar collectors based on the predicted parameters shown in Figures 6 and 8. The results shown in Figure 22, however, indicate that, compared with the normal combined operation mode, a small portion of heat was abandoned during OTC operation when the system was stopped during the low-efficiency period.

Nevertheless, as shown in Figures 23 and 24, the daily accumulated energy consumption of OTC operation mode was much lower than that of the normal combined operation mode. The daily accumulated TEC of OTC operation mode was also much higher than the normal combined operation mode. Although the thermal compensation quantity under OTC operation mode was $75.7 \%$ of that under conventional

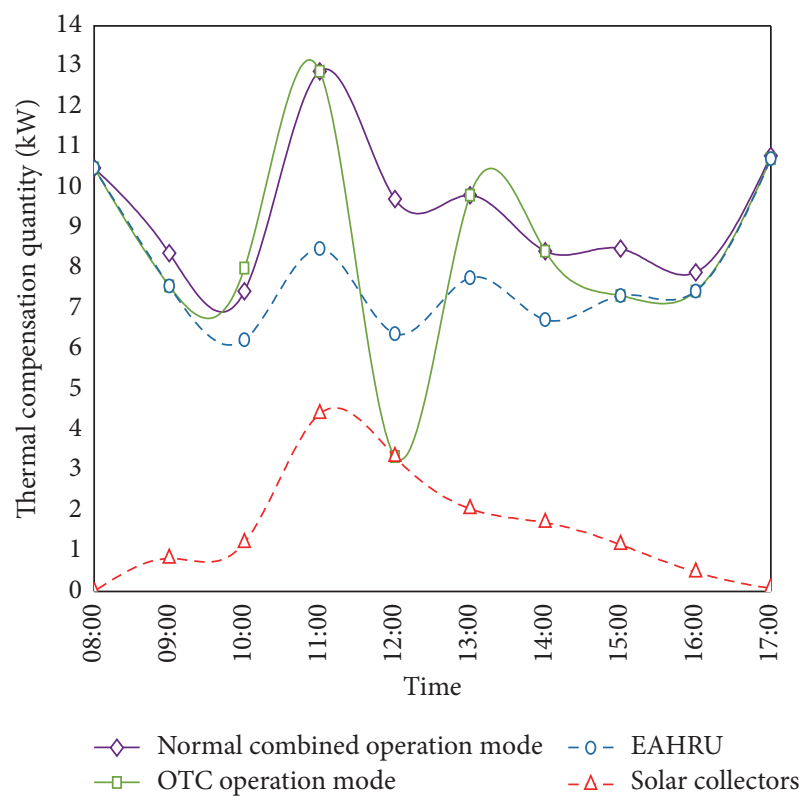

FIGURE 20: Thermal compensation quantity of combined operation mode and OTC operation mode on a typical day.

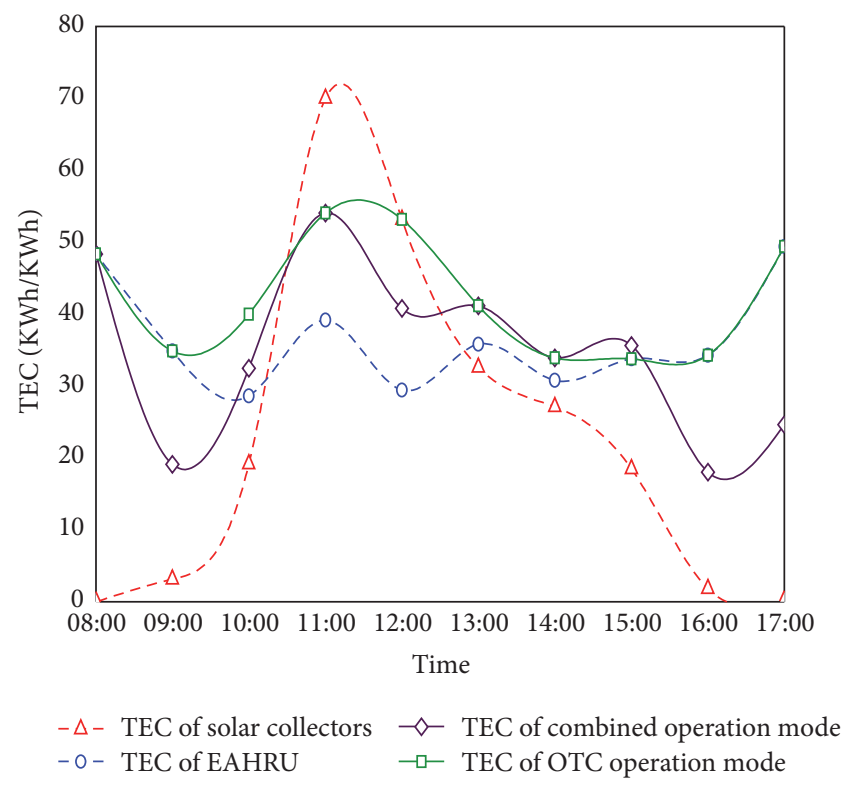

FIGURE 21: TEC of combined operation mode and OTC operation mode on a typical day.

one, the corresponding electrical energy was merely $55.6 \%$, which means OTC operation mode is superior to normal one.

Figure 25 illustrates the yearly comparison of TEC, energy consumption, and thermal compensation of the OTC operation mode and traditional combined operation mode. As shown in Figure 25, the measured yearly accumulated energy cost and accumulated thermal compensation quantity of the OTC operation mode were $59.1 \%$ and $73.8 \%$ of the corresponding values of the normal combined operation 


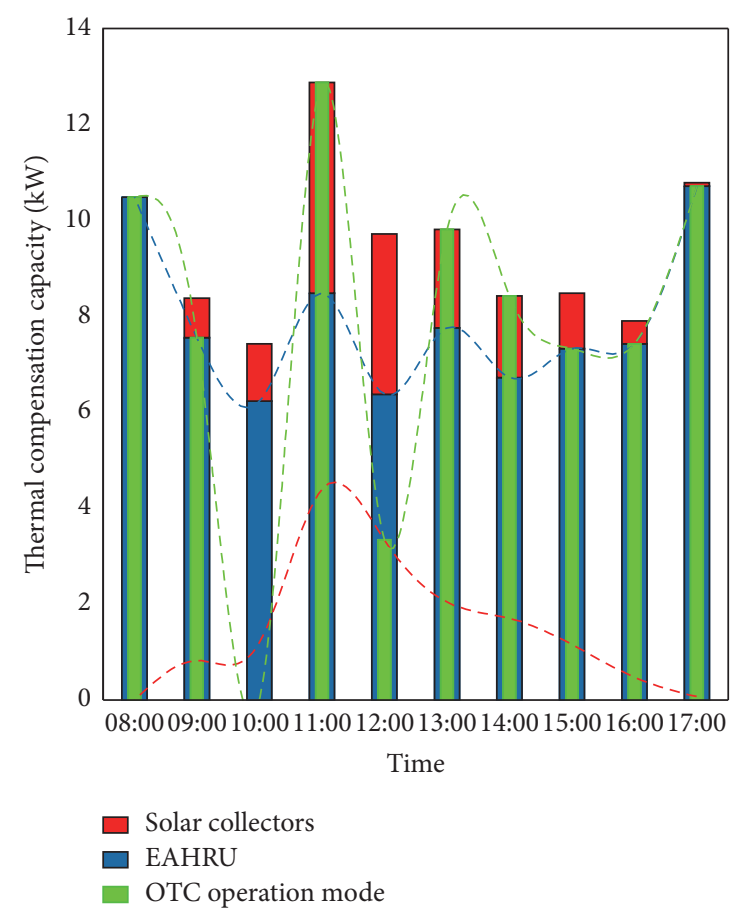

FIgURE 22: Comparison of hourly thermal compensation quantity on a typical day.

mode. Thus, the yearly TEC of the OTC operation mode was 1.25 times as high as the TEC of the normal operation mode.

5.7. Estimation of Macroscale Benefit of OTC Method. The ESTC system and OTC method exhibits favorable potential application. As indicated in the "13th Five-Year" national development plan of China, by 2020 , the cumulative application building area of ground-source heat pump is expected to reach 1.6 billion square meters. Specially, the corresponding heating area in cold region of China will exceed 500 million square meters, and $60 \%$ of this area will require thermal compensation. Compared with conventional thermal compensation system, the annual saved electricity achieved by applying ESTC system for thermal compensation in OTC mode will be $7.68 \times 10^{8} \mathrm{kWh} / \mathrm{yr}$., which means 113.2 million US dollars for energy expenses will be reduced each year and the carbon dioxide emission will decrease by $7.66 \times$ $10^{5}$ Ton/yr. Furthermore, more considerable energy consumption reduction can be expected if the proposed ESTC system and OTC method are adopted in other countries.

\section{Conclusions}

To improve the thermal compensation efficiency of GCHP systems in cold regions, an ESTC thermal compensation system which integrated an ETD room exhaust air heat recovery system and a solar energy system was proposed in this study. An optimized thermal compensation method (OTC method) based on the prediction of the next day's exhaust air temperature and the solar irradiance was also

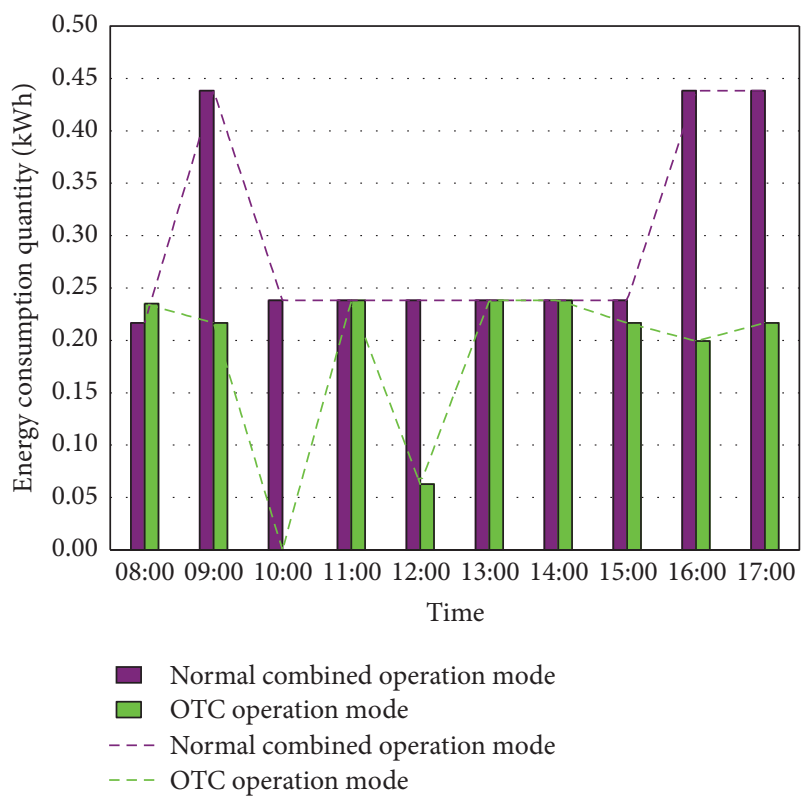

FIGURE 23: Comparison of hourly energy consumption quantity of combined operation mode and OTC operation mode on a typical day.

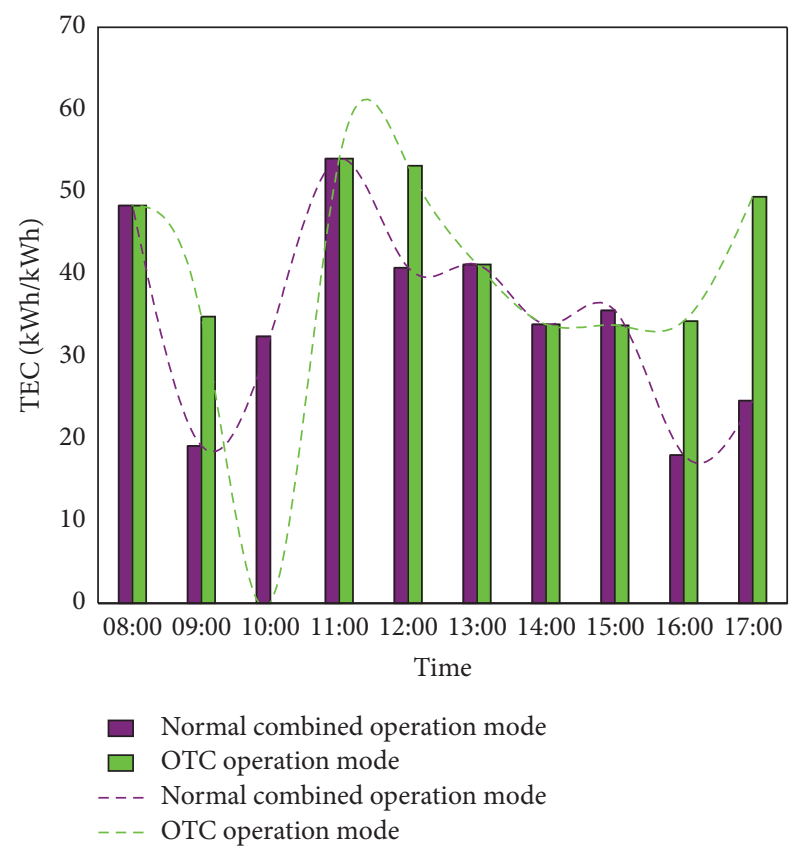

FIGURE 24: Comparison of hourly TEC of combined operation mode and OTC mode on a typical day.

proposed and investigated. Moreover, a modified STSDG method was presented and utilized for predicting the solar irradiance. An operation experiment and a series of TRNSYS simulations were conducted to evaluate the ESTC system and those two approaches. Based on the results of the experiment and simulations, the following conclusions were drawn: 


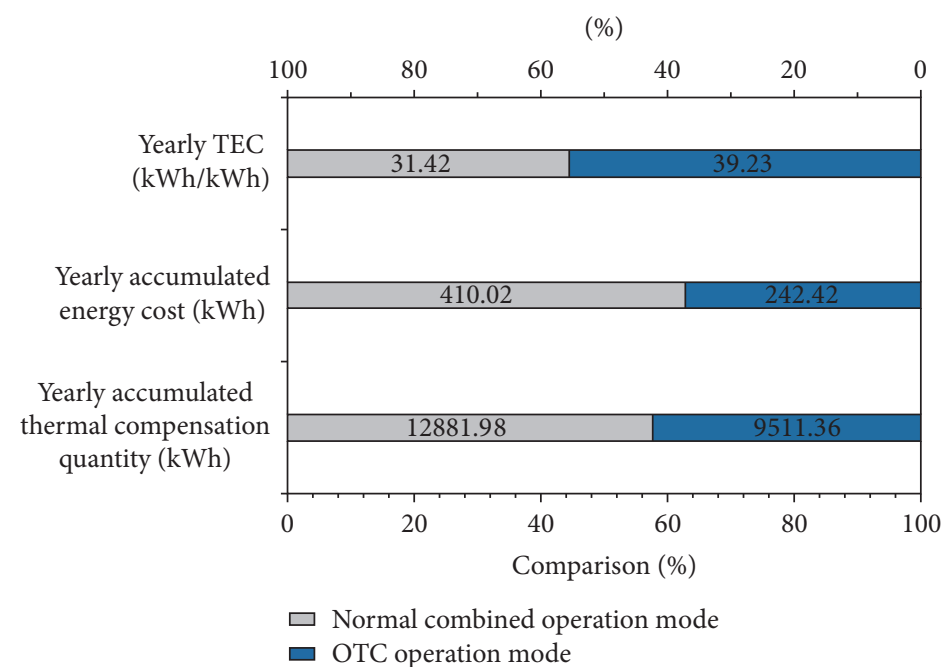

FIGURE 25: Comparison of annual performance of combined operation mode and OTC mode during January 12, 2015-January $12,2016$.

(1) The ESTC system including ETD room exhaust air heat recovery and solar energy components can effectively compensate heat to the ground heat exchanger. During the 10-year simulation period, the simulated TIR of the ESTC -GCHP was below 2.5\%; the calculated TIR based on experimental data in the first year was $-2.16 \%$.

(2) The correlation between the daily maximum values of global solar irradiance and AQI was relatively high in a typical winter month; $R^{2}$ of the linear correlation between these two values was 0.516 and the correlation coefficient $(R)$ was -0.719 . Thus, it is quite necessary to introduce the AQI correction factor in the modified STSDG method or other prediction methods to improve the prediction accuracy of global solar irradiance in weather conditions that include heavy air pollution.

(3) Compared with the traditional STSDG method, the prediction accuracy of the modified STSDG method was significantly improved in the hazy weather with high AQI. For the accumulated solar irradiance of the four highest radiation hours, the MAPE between the predicted and measured values was $6.35 \%$.

(4) By using the OTC method, the energy consumption of the thermal compensation process was reduced significantly. The TEC of this approach was 1.25 times as high as the traditional combined operation method.

These results indicated that both the ESTC system and the OTC method are effective and highly efficient. This study will promote more efficient and extensive application of solar-GCHP systems and exhaust air heat recovery systems. Moreover, the ideas of OTC method and the modified STSDG method can also be applied to further researches on other hybrid-GCHP systems or hybrid solar energy systems.

\section{Nomenclature}

a: $\quad$ Empirical constants

$a_{1}$ : $\quad$ A constant which puts $T^{*}$ as a reference

$a_{2}$ : A constant which puts $T^{*}$ as a reference

$A_{C}: \quad$ The gross collector area $\left(\mathrm{m}^{2}\right)$

$b$ : $\quad$ Empirical constants

CL: $\quad$ Cloud amount

$f: \quad$ Solar fraction (\%)

G: $\quad$ Total solar irradiance $\left(\mathrm{W} / \mathrm{m}^{2}\right)$

$H$ : The total horizontal solar radiance $\left(\mathrm{W} / \mathrm{m}^{2}\right)$

$H_{0}$ : Horizontal solar irradiance outside the atmosphere $\left(\mathrm{W} / \mathrm{m}^{2}\right)$

$J_{T}: \quad$ The hourly solar irradiance quantity $\left(\mathrm{J} / \mathrm{m}^{2} \cdot \mathrm{h}\right)$

$K_{t}: \quad$ Clearness index

$P_{c}: \quad$ Thermal compensation quantity (kWh)

$P_{i}$ : $\quad$ Power consumption of thermal compensation (kWh)

$Q_{\mathrm{AHE}}$ : The annual accumulated heat extracted from the ground $(\mathrm{kWh})$

$Q_{\text {AHR }}$ : The annual accumulated heat rejected into the ground (kWh)

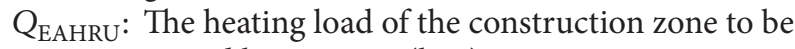
served by EAHRU (kW)

$Q_{H}$ : The heat-collecting capacity of the solar collector (W)

$Q_{\text {tot }}$ : The total heating load of the building ( $\left.\mathrm{kW}\right)$

$Q_{\mathrm{re}}$ : The annual accumulated heat recovery $(\mathrm{kWh})$

$R: \quad$ Correlation coefficient

$t_{1}$ : The working medium inlet temperature of the solar collector $\left({ }^{\circ} \mathrm{C}\right)$

$t_{a}: \quad$ The ambient temperature $\left({ }^{\circ} \mathrm{C}\right)$

T: $\quad$ Time (hr)

$T^{*}: \quad$ The normalized temperature difference $\left(\mathrm{m}^{2} \cdot \mathrm{K} / \mathrm{W}\right)$

$x$ : $\quad$ Hourly dry-bulb temperatures $\left({ }^{\circ} \mathrm{C}\right)$

$x_{\text {avg }}$ : Average temperature between $\left({ }^{\circ} \mathrm{C}\right)$

$x_{h}: \quad$ Forecasted maximum temperature $\left({ }^{\circ} \mathrm{C}\right)$ 
$x_{l}: \quad$ Forecasted minimum temperature $\left({ }^{\circ} \mathrm{C}\right)$

$x_{p \text {,max }}:$ predicted maximum dry-bulb temperature $\left({ }^{\circ} \mathrm{C}\right)$

$x_{p \text {,min }}$ : Predicted minimum dry-bulb temperature

$\left({ }^{\circ} \mathrm{C}\right)$

$\widehat{X}: \quad$ Predicted value $\left({ }^{\circ} \mathrm{C}\right)$.

\section{Abbreviations}

AGO: Accumulated generating operation

APE: $\quad$ Absolute Percentage Error

AQI: $\quad$ Air quality Index

DeST: An Integrated Building Simulation Toolkit

EAHRU: Exhaust air heat recovery unit

ESTC: Exhaust air heat recovery and solar energy combined thermal compensation system

ETD: Electricity transformation and distribution

GCHP: Ground-coupled heat pump

HVAC: Heating, Ventilating and Air Conditioning

MAPE: Mean absolutely percentage error

GM: $\quad$ Grey model

$\operatorname{GM}(1,1)$ : Grey model $(1,1)$

OTC: Optimized thermal compensation

STSDG: Solar term similar days group

TEC: Thermal compensation capacity per unit energy Consumption

TIR: Thermal imbalance ratio.

\section{Greek Letters}

$\delta_{h}$ : Scale factor for maximum temperature

$\delta_{l}$ : Scale factor for minimum temperature

$\eta_{c}$ : The average efficiency of solar collector based on the gross collector area (\%)

$\eta_{L}$ : Heat loss rate of pipeline and heat storage device (\%).

\section{Competing Interests}

The authors declare that they have no competing interests.

\section{Acknowledgments}

This work was financially supported by the National Natural Science Foundation of China (Project no. 51578220). The authors would like to express the heartfelt thanks to all people participating in the experiments.

\section{References}

[1] Z. Qi, Q. Gao, Y. Liu, Y. Y. Yan, and J. D. Spitler, "Status and development of hybrid energy systems from hybrid ground source heat pump in China and other countries," Renewable and Sustainable Energy Reviews, vol. 29, pp. 37-51, 2014.

[2] X. Q. Zhai, M. Qu, X. Yu, Y. Yang, and R. Z. Wang, "A review for the applications and integrated approaches of ground-coupled heat pump systems," Renewable and Sustainable Energy Reviews, vol. 15, no. 6, pp. 3133-3140, 2011.
[3] I. Sarbu and C. Sebarchievici, "General review of ground-source heat pump systems for heating and cooling of buildings," Energy and Buildings, vol. 70, pp. 441-454, 2014.

[4] X. Li, Z. Chen, and J. Zhao, "Simulation and experiment on the thermal performance of U-vertical ground coupled heat exchanger," Applied Thermal Engineering, vol. 26, no. 14-15, pp. 1564-1571, 2006.

[5] C. Xi, L. Lin, and Y. Hongxing, "Long term operation of a solar assisted ground coupled heat pump system for space heating and domestic hot water," Energy and Buildings, vol. 43, no. 8, pp. 1835-1844, 2011.

[6] Z. Liu, W. Xu, C. Qian, X. Chen, and G. Jin, "Investigation on the feasibility and performance of ground source heat pump (GSHP) in three cities in cold climate zone, China," Renewable Energy, vol. 84, pp. 89-96, 2015.

[7] W. Yang, Y. Chen, M. Shi, and J. D. Spitler, "Numerical investigation on the underground thermal imbalance of groundcoupled heat pump operated in cooling-dominated district," Applied Thermal Engineering, vol. 58, no. 1-2, pp. 626-637, 2013.

[8] H. Cho and J. M. Choi, "The quantitative evaluation of design parameter's effects on a ground source heat pump system," Renewable Energy, vol. 65, pp. 2-6, 2014.

[9] R. Fan, Y. Gao, Y. Pan, and Y. Zhang, "Research on cool injection and extraction performance of borehole cool energy storage for ground coupled heat pump system," Energy and Buildings, vol. 101, pp. 35-44, 2015.

[10] M. Yu, K. Zhang, X. Cao, A. Hu, P. Cui, and Z. Fang, “Zoning operation of multiple borehole ground heat exchangers to alleviate the ground thermal accumulation caused by unbalanced seasonal loads," Energy and Buildings, vol. 110, pp. 345-352, 2016.

[11] W. Ji, T. You, S. Bai, W. Shi, and B. Wang, "Effects of ground heat exchanger design parameters on performance of ground-source heat pump systems in cold zone," Journal of HV\&AC, no. 3, pp. 113-118, 2015.

[12] Q. Zhang, N. Lv, S. Chen, H. Shi, and Z. Chen, "Study on operating and control strategies for hybrid ground source heat pump system," Procedia Engineering, vol. 121, pp. 1894-1901, 2015.

[13] K. Allaerts, M. Coomans, and R. Salenbien, "Hybrid groundsource heat pump system with active air source regeneration," Energy Conversion and Management, vol. 90, pp. 230-237, 2015.

[14] R. Fan, Y. Gao, L. Hua, X. Deng, and J. Shi, “Thermal performance and operation strategy optimization for a practical hybrid ground-source heat-pump system," Energy and Buildings, vol. 78, pp. 238-247, 2014.

[15] M. Guo, N. Diao, Y. Man, and Z. Fang, "Research and development of the hybrid ground-coupled heat pump technology in China," Renewable Energy, vol. 87, part 3, pp. 1033-1044, 2016.

[16] G. Emmi, A. Zarrella, M. De Carli, and A. Galgaro, "An analysis of solar assisted ground source heat pumps in cold climates," Energy Conversion and Management, vol. 106, pp. 660-675, 2015.

[17] P. Pinel, C. A. Cruickshank, I. Beausoleil-Morrison, and A. Wills, "A review of available methods for seasonal storage of solar thermal energy in residential applications," Renewable and Sustainable Energy Reviews, vol. 15, no. 7, pp. 3341-3359, 2011.

[18] K. Bakirci, O. Ozyurt, K. Comakli, and O. Comakli, "Energy analysis of a solar-ground source heat pump system with vertical closed-loop for heating applications," Energy, vol. 36, no. 5, pp. 3224-3232, 2011. 
[19] E. Wang, A. S. Fung, C. Qi, and W. H. Leong, "Performance prediction of a hybrid solar ground-source heat pump system," Energy and Buildings, vol. 47, pp. 600-611, 2012.

[20] A. D. Chiasson and C. Yavuzturk, "Assessment of the viability of hybrid geothermal heat pump systems with solar thermal collectors," Ashrae Transactions, vol. 109, pp. 487-500, 2003.

[21] F. M. Rad, A. S. Fung, and W. H. Leong, "Feasibility of combined solar thermal and ground source heat pump systems in cold climate, Canada," Energy and Buildings, vol. 61, pp. 224-232, 2013.

[22] Q. Si, M. Okumiya, and X. Zhang, "Performance evaluation and optimization of a novel solar-ground source heat pump system," Energy and Buildings, vol. 70, pp. 237-245, 2014.

[23] W. Yang, L. Sun, and Y. Chen, "Experimental investigations of the performance of a solar-ground source heat pump system operated in heating modes," Energy and Buildings, vol. 89, pp. 97-111, 2015.

[24] Z. Han, M. Zheng, F. Kong, F. Wang, Z. Li, and T. Bai, "Numerical simulation of solar assisted ground-source heat pump heating system with latent heat energy storage in severely cold area," Applied Thermal Engineering, vol. 28, no. 11-12, pp. 1427-1436, 2008.

[25] X. Wang, M. Zheng, W. Zhang, S. Zhang, and T. Yang, "Experimental study of a solar-assisted ground-coupled heat pump system with solar seasonal thermal storage in severe cold areas," Energy and Buildings, vol. 42, no. 11, pp. 2104-2110, 2010.

[26] M. Z. Khan, M. R. Al-Mamun, S. Sikdar, P. K. Halder, and M. R. Hasan, "Design, fabrication, and efficiency study of a novel solar thermal water heating system: towards sustainable development," International Journal of Photoenergy, vol. 2016, Article ID 9698328, 8 pages, 2016.

[27] M. Yahya, "Design and performance evaluation of a solar assisted heat pump dryer integrated with biomass furnace for red chilli," International Journal of Photoenergy, vol. 2016, Article ID 8763947, 14 pages, 2016.

[28] N. Zhu, P. Hu, L. Xu, Z. Jiang, and F. Lei, "Recent research and applications of ground source heat pump integrated with thermal energy storage systems: a review," Applied Thermal Engineering, vol. 71, no. 1, pp. 142-151, 2014.

[29] T. You, W. Shi, B. Wang, W. Wu, and X. Li, "A new groundcoupled heat pump system integrated with a multi-mode airsource heat compensator to eliminate thermal imbalance in cold regions," Energy and Buildings, vol. 107, pp. 103-112, 2015.

[30] W. Wu, X. Li, T. You, B. Wang, and W. Shi, "Hybrid ground source absorption heat pump in cold regions: thermal balance keeping and borehole number reduction," Applied Thermal Engineering, vol. 90, pp. 322-334, 2015.

[31] D. Liu, F.-Y. Zhao, and G.-F. Tang, "Active low-grade energy recovery potential for building energy conservation," Renewable and Sustainable Energy Reviews, vol. 14, no. 9, pp. 2736-2747, 2010.

[32] M. Justo Alonso, P. Liu, H. M. Mathisen, G. Ge, and C. Simonson, "Review of heat/energy recovery exchangers for use in ZEBs in cold climate countries," Building and Environment, vol. 84, pp. 228-237, 2015.

[33] D. O'connor, J. K. S. Calautit, and B. R. Hughes, "A review of heat recovery technology for passive ventilation applications," Renewable and Sustainable Energy Reviews, vol. 54, pp. 14811493, 2016.

[34] “Technical code for solar heating system,” Tech. Rep. GB504952009, China Building Industry Press, 2009.
[35] ASHRAE, "Methods of testing to determine the performance of solar collectors," ASHRAE Standard 93-2003, ASHRAE, Atlanta, Ga, USA, 2003.

[36] Q. Zhou, S. Wang, X. Xu, and F. Xiao, "A grey-box model of next-day building thermal load prediction for energy-efficient control," International Journal of Energy Research, vol. 32, no. 15, pp. 1418-1431, 2008.

[37] J. L. Deng, "Introduction to grey system theory," The Journal of Grey System, vol. 1, no. 1, pp. 1-24, 1989.

[38] N. Li, K. Wang, and J. Cheng, "A research on a following day load simulation method based on weather forecast parameters," Energy Conversion and Management, vol. 103, pp. 691-704, 2015.

[39] M. Collares-Pereira and A. Rabl, "The average distribution of solar radiation-correlations between diffuse and hemispherical and between daily and hourly insolation values," Solar Energy, vol. 22, no. 2, pp. 155-164, 1979.

[40] B. Y. H. Liu and R. C. Jordan, "The interrelationship and characteristic distribution of direct, diffuse and total solar radiation," Solar Energy, vol. 4, no. 3, pp. 1-19, 1960.

[41] B. Z. Wang, "Lectures on the calculation of solar radiation 1 lecture: the calculation of astronomical parameters in solar energy utilization," Solar Energy, vol. 2, pp. 8-10, 1999 (Chinese).

[42] S. E. Tuller, "The relationship between diffuse, total and extra terrestrial solar radiation," Solar Energy, vol. 18, no. 3, pp. 259263, 1976.

[43] H. Ikeda and A. Ichiki, "Relationship between the clearness index and the global solar radiation," Journal of Meteorological Research, vol. 29, pp. 117-125, 1977.

[44] Z. Z. Huang and Y. Q. Pan, "A calculation method of hourly solar irradiance based on statistic data," in Proceedings of the Shanghai Refrigeration Society Annual Conference, 2005.

[45] W. X. Yao, Zh. R. Li, C. Li, and Zh. T. Ai, "Relationship between solar radiation and solar illuminance under all climate conditions," Journal of Tongji University (Nature Science), vol. 5, pp. 784-787, 2013.

[46] S. Rehman and S. G. Ghori, "Spatial estimation of global solar radiation using geostatistics," Renewable Energy, vol. 21, no. 3-4, pp. 583-605, 2000.

[47] N. Ma and M. Liu, "The impact and durative effect of the measures of securing quality air for the Beijing Olympic and Paralympics Games 2008 on air pollution index in Beijing," Chinese Journal of Preventive Medicine, vol. 43, no. 6, pp. 517521, 2009.

[48] J.-L. An, Y.-S. Wang, X. Li, Y. Sun, and S.-H. Shen, "Relationship between surface UV radiation and air pollution in Beijing," Environmental Science, vol. 29, no. 4, pp. 1053-1058, 2008.

[49] Y. Qi, S.-B. Fang, and W.-Z. Zhou, "Correlative analysis between the changes of surface solar radiation and its relationship with air pollution, as well as meteorological factor in East and West China in recent 50 years," Wuli Xuebao/Acta Physica Sinica, vol. 64, no. 8, Article ID 089201, 2015.

[50] W. Wang, Y. Li, Y. Sun, G. Li, L. Wang, and L. Shao, "Design of device for simulating haze-caused radiation changes in open field and its effect," Journal of Agricultural Engineering, vol. 31, no. 13, pp. 199-206, 2015.

[51] Q. H. Tao, Z. R. Li, and F. J. Jiang, "Estimation of incident daily solar radiation from meteorology and air quality observation," Journal of Jimei University (Natural Science), vol. 19, no. 5, pp. 369-374, 2014 (Chinese).

[52] Ministry of Environmental Protection, "Technical regulation on ambient air quality index," HJ 633-2012, Ministry of Enviromental Protection of the People's Republic of China, 2012. 
[53] S. Mohanty, P. K. Patra, and S. S. Sahoo, "Prediction and application of solar radiation with soft computing over traditional and conventional approach-a comprehensive review," Renewable and Sustainable Energy Reviews, vol. 56, pp. 778-796, 2016.

[54] R. Fan, D. Z. Meng, D. S. Xu, D. O. Mathematics, and S. I. University, "Survey of research process on statistical correlation analysis," Mathematical Modeling and Its Applications, vol. 3, no. 1, pp. 1-12, 2014 (Chinese).

[55] T. You, B. Wang, W. Wu, W. Shi, and X. Li, "A new solution for underground thermal imbalance of ground-coupled heat pump systems in cold regions: heat compensation unit with thermosyphon," Applied Thermal Engineering, vol. 64, no. 1-2, pp. 283-292, 2014. 

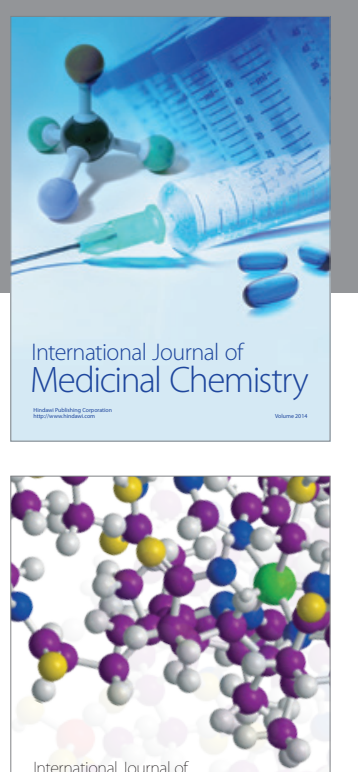

Carbohydrate Chemistry

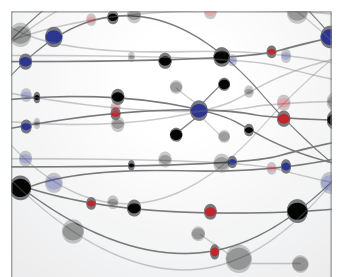

The Scientific World Journal
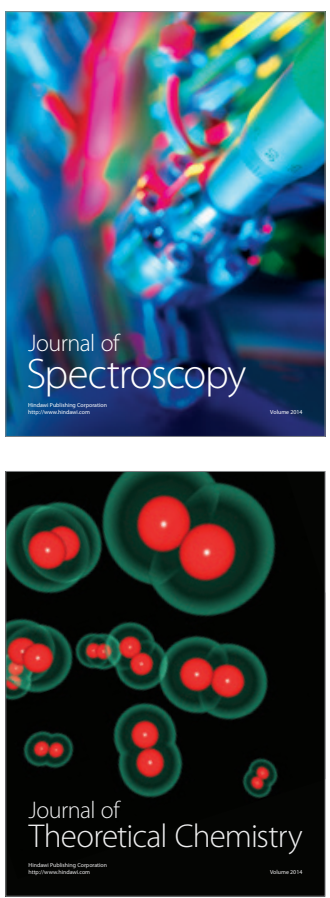
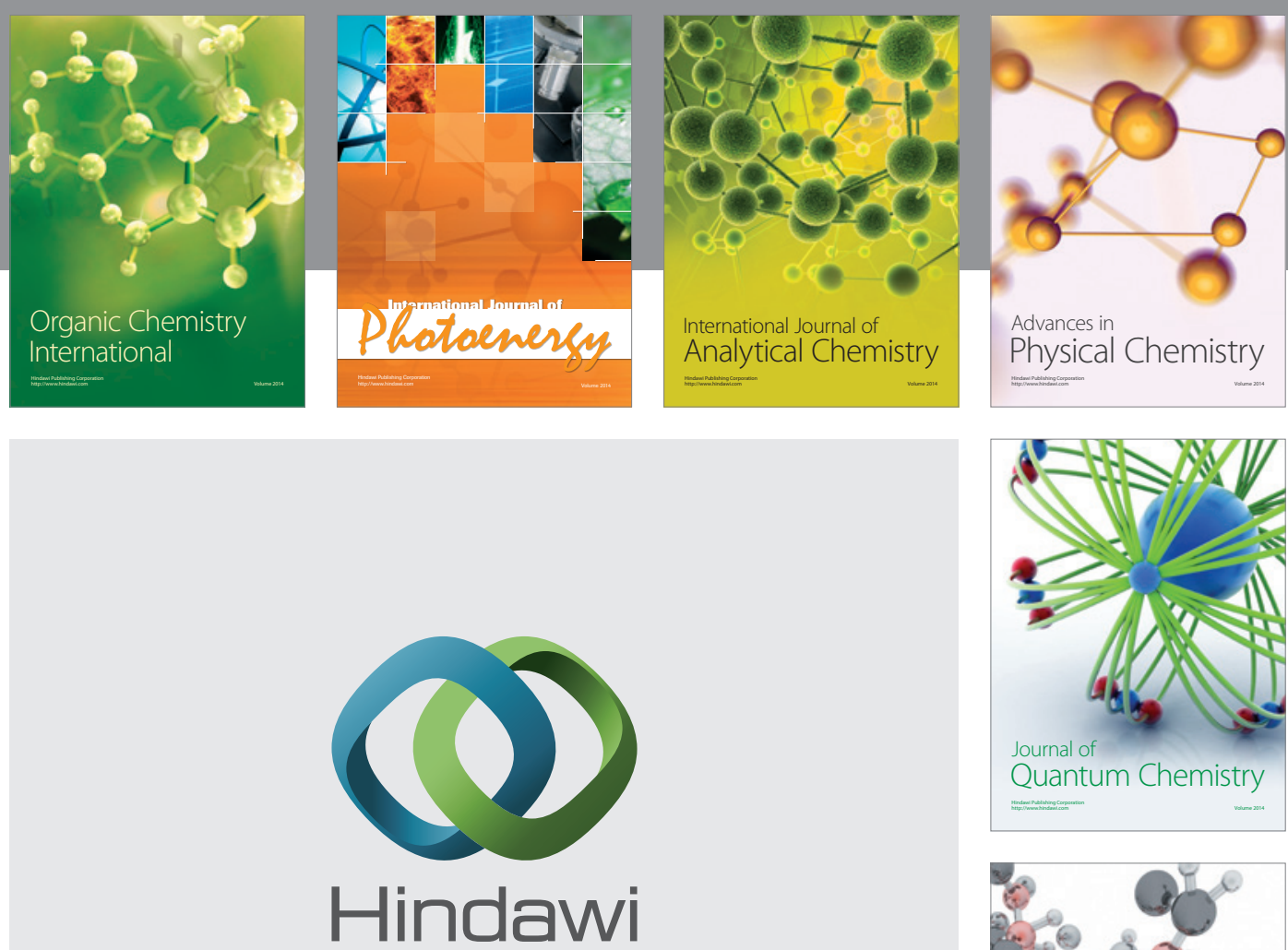

Submit your manuscripts at

https://www.hindawi.com

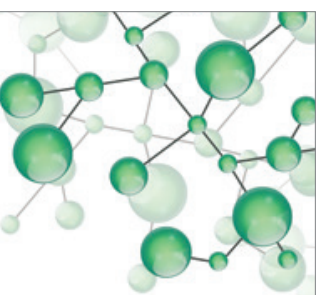

International Journal of

Inorganic Chemistry
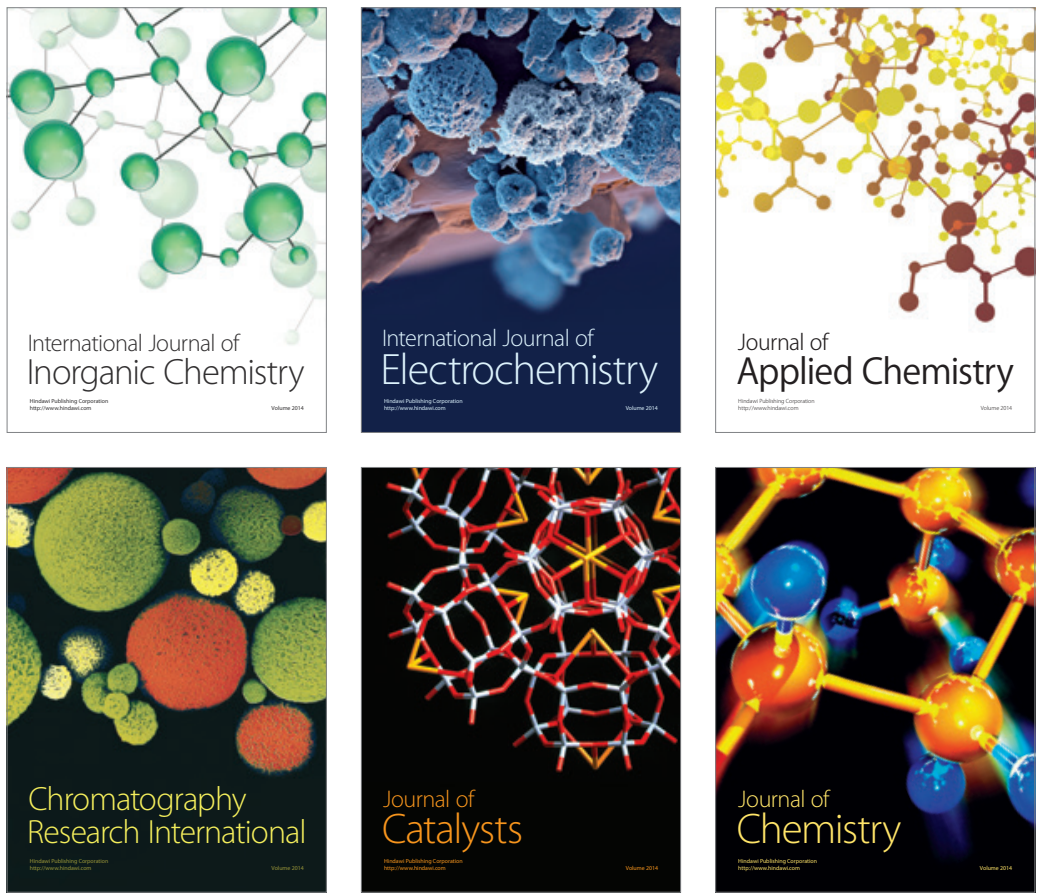

Journal of

Applied Chemistry
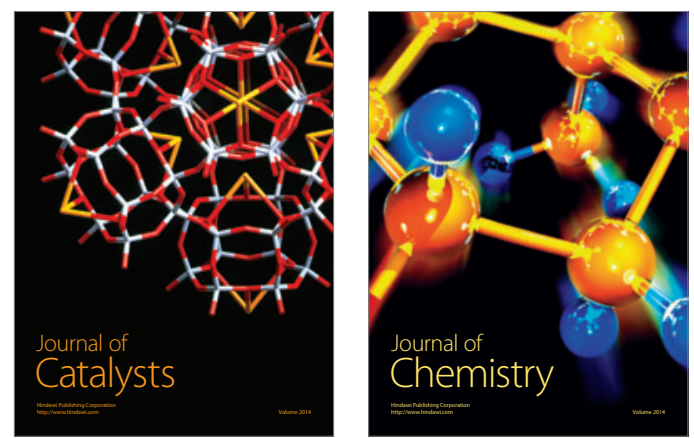
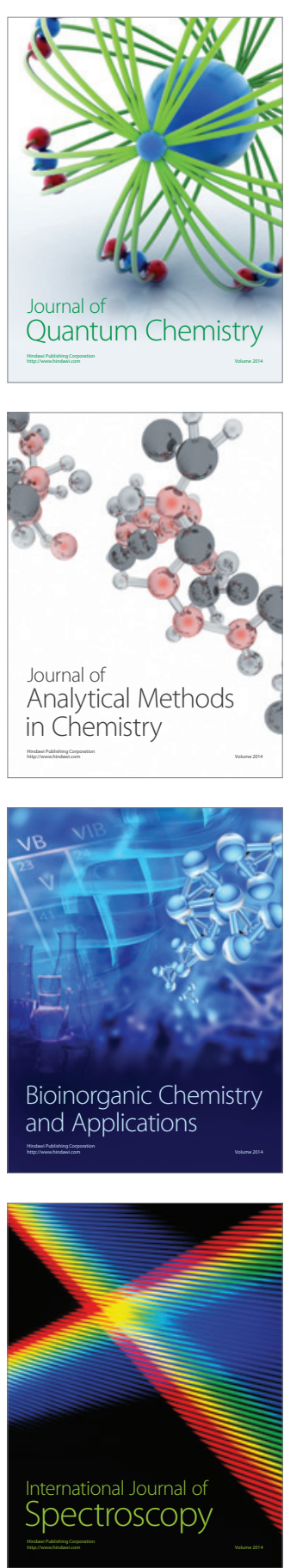